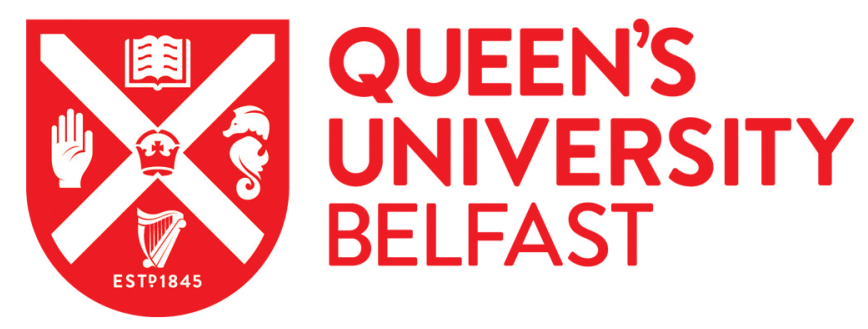

\title{
The role of interfacial properties on the intralaminar and interlaminar damage behaviour of unidirectional composite laminates: Experimental characterization and multiscale modelling
}

Tan, W., Naya, F., Yang, L., Chang, T., Falzon, B. G., Zhan, L., Molina-Aldareguía, J. M., González, C., \& Llorca, J. (2018). The role of interfacial properties on the intralaminar and interlaminar damage behaviour of unidirectional composite laminates: Experimental characterization and multiscale modelling. Composites Part B: Engineering, 138, 206-221. https://doi.org/10.1016/j.compositesb.2017.11.043

Published in:

Composites Part B: Engineering

Document Version:

Peer reviewed version

Queen's University Belfast - Research Portal:

Link to publication record in Queen's University Belfast Research Portal

\begin{abstract}
Publisher rights
Copyright 2017 Elsevier.

This manuscript is distributed under a Creative Commons Attribution-NonCommercial-NoDerivs License

(https://creativecommons.org/licenses/by-nc-nd/4.0/), which permits distribution and reproduction for non-commercial purposes, provided the author and source are cited.

\section{General rights}

Copyright for the publications made accessible via the Queen's University Belfast Research Portal is retained by the author(s) and / or other copyright owners and it is a condition of accessing these publications that users recognise and abide by the legal requirements associated with these rights.
\end{abstract}

Take down policy

The Research Portal is Queen's institutional repository that provides access to Queen's research output. Every effort has been made to ensure that content in the Research Portal does not infringe any person's rights, or applicable UK laws. If you discover content in the Research Portal that you believe breaches copyright or violates any law, please contact openaccess@qub.ac.uk. 


\title{
The role of interfacial properties on the intralaminar and interlaminar
}

\section{damage behaviour of unidirectional composite laminates: experimental characterization and multiscale modelling}

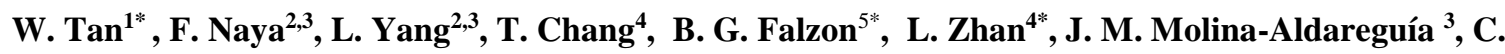 \\ González $^{2,3}$, J. Llorca ${ }^{2,3}$ * \\ ${ }^{1}$ Cambridge University Engineering Department, Trumpington Street, Cambridge CB2 1PZ, UK \\ ${ }^{2}$ Department of Materials Science, Polytechnic University of Madrid, E.T.S. de Ingenieros de Caminos, 28040 \\ Madrid, Spain \\ ${ }^{3}$ IMDEA Materials Institute, C/Eric Kandel 2, 28906, Getafe, Madrid, Spain \\ ${ }^{4}$ State Key Laboratory of High-performance Complex Manufacturing, Central South University, Changsha, \\ 410083, P.R.China \\ ${ }^{5}$ School of Mechanical and Aerospace Engineering, Queen's University Belfast, Belfast, BT9 5AH, UK \\ * Corresponding Authors: W. Tan (wei.tan@eng.cam.ac.uk), B.G. Falzon (ㅁ․falzon@qub.ac.uk), L. Zhan (yjs- \\ cast@csu.edu.cn), J. Llorca (javier.llorca@upm.es)
}

\begin{abstract}
The development of the latest generation of wide-body passenger aircraft has heralded a new era in the utilisation of carbon-fibre composite materials. One of the primary challenges facing future development programmes is the desire to reduce the extent of physical testing, required as part of the certification process, by adopting a 'certification by simulation' approach. A hierarchical bottom-up multiscale simulation scheme can be an efficient approach that takes advantage of the natural separation of length scales between different entities
\end{abstract}


(fibre/matrix, ply, laminate and component) in composite structures. In this work, composites with various fibre/matrix and interlaminar interfacial properties were fabricated using an autoclave under curing pressures ranging from 0 to $0.8 \mathrm{MPa}$. The microstructure (mainly void content and spatial distribution) and the mechanical properties of the matrix and fibre/matrix interface were measured, the latter by means of nano-indentation tests in matrix pockets, and fibre push-in tests. In addition, the macroscopic interlaminar shear strength was determined by means of three-points bend tests on short beams. To understand the influence of interfacial properties on the intralaminar failure behaviour, a high-fidelity microscale computational model is presented to predict homogenized ply properties under shear loading. Predicted ply material parameters are then transferred to a mesoscale composite damage model to reveal the interaction between intralaminar and interlaminar damage behaviour of composite laminates.

Keywords: A. Polymer-matrix composites (PMCs); B. Interface/interphase; C. Damage mechanics; C. Computational modelling

\section{Introduction}

Carbon fibre reinforced composite materials are nowadays widely used in aero-structural components due to their high specific stiffness and strength. Nevertheless, composite structures are susceptible to damage from lowvelocity impact events leading to a significant reduction in compression- after-impact residual strength [1]. Another major challenge is to ensure a prescribed level of crashworthiness of fibre-reinforced composite vehicles [2]. The premise of superior material properties of composites, is currently tempered by high development costs, slow production rates and lengthy and expensive certification programmes. Substantial effort is currently being directed towards the development of new modelling and simulation tools, at all levels of the development cycle, to mitigate these shortcomings.

Physically-based approaches, quantitatively accounting for the progression of the actual damage mechanisms has been widely developed to model damage behaviour under various loading conditions [1-8]. The key feature of these models is to take into account all possible failure modes and their complex interactions. Typical damage modes occurring in composite laminates consist of a combination of intralaminar damage (such as matrix cracking or plasticity, fibre/matrix debonding and fibre fracture) and interlaminar damage, which develops at the interface between adjacent plies in the form of debonding between layers (delamination). Mesoscale models 
based on fracture and continuum damage mechanics (CDM) are currently the most popular method for the failure prediction of composite material. In order to deal with all the intralaminar damage mechanisms within a single framework, CDM treats the lamina as a homogeneous and anisotropic solid. This simplification is valid in most of the cases, except some particular cases when composite plies are subjected to large shear deformation. In this scenario, strain components are calculated from the symmetric part of the deformation gradient and, therefore, shear deformation parallel or perpendicular to the fibres leads to the same response, which is not the actual behaviour. Shear parallel to the fibres leads to failure by the localization of shear deformation in the matrix (and the shear strength is similar to the matrix shear strength) while shear perpendicular to the fibres induces fibre rotation and a marked strain hardening effect associated with the load taken up by the fibres $[9,10]$. This fibre rotation effect is not directly taken into account in the CDM framework.

The predictive capability of CDM models to accurately capture the damage behaviour of composite structures relies on the acquisition of accurate material properties [11]. These input material parameters have to be obtained through experimental campaigns for individual material systems. Results obtained for a given unidirectional composite ply cannot be directly extrapolated to other plies with different fibre volume fraction or constituent properties, leading to an extensive investment in their physical characterization. However, micromechanical models, in which the matrix and interface mechanical properties are obtained by means of in situ testing, offers a novel approach to understand the deformation and fracture mechanisms. Naya et al. [12] have demonstrated high accuracy in the prediction of the mechanical behaviour, including fracture mechanisms under complex multiaxial loading cases. A micromechanical model considering fibre rotation is able to capture this non-linear effect under large deformation shear loading [9]. It can also be used to determine the fracture resistance (toughness) of an individual ply [13] and the fatigue behaviour [14]. This provides a very powerful virtual testing tool to understand micromechanical failure mechanisms and predict material constants for the mesoscale model.

In this work, a novel multi-scale model is presented to provide a framework to understand the effect of interface properties on the intralaminar and interlaminar failure behaviour of composite laminates. Composite laminates with various intra/interlaminar properties were manufactured by curing under pressure. Verification of microscale and mesoscale model was carried out by simulating the interfacial characterization tests. Excellent qualitative and quantitative correlation was achieved between the numerical models and experimental results. In particular, the micromechanical model was able to capture the failure modes under transverse 
tension/compression and shear perpendicular to fibre direction. Strain hardening effect due to fibre rotation was also observed under shear perpendicular to the fibre direction. The fibre rotation effect, in the mesoscale model, is explicitly modelled using the predicted non-linear stress strain curves from the microscale model. The numerical mesoscale modelling results were in excellent agreement with the experiment in terms of non-linear behaviour. The fidelity of the computational models provided detailed information on the initiation and propagation of damage in microscale and mesoscale model. These results enabled a deeper understanding of the effect of interfacial properties on the fracture processes and on the mechanical properties at the micro and macro scales in unidirectional composite laminates.

\section{Multiscale model}

As shown in Figure 1, a bottom-up multiscale virtual testing strategy is proposed to take into account the physical mechanisms of deformation at different length scales on the behaviour of the composite [15-17]. This study also enables carrying out multiscale modelling by computing the properties of individual ply and homogenizing the results into a constitutive model, followed by the transfer of information to the next length scale. In the bottom level of the multiscale modelling approach, micromechanical characterization techniques (nanoindentation, microbond tests, etc) are used to measure the properties of the constituents in the composite. Computational homogenization of a Representative Volume Element (RVE) of the microstructure is then used to predict the ply properties from the properties of the constituents (fibre, matrix and interfaces) together with the volume fraction and spatial distribution of the fibres within an individual ply. Mesoscale models use the homogenized results of the micromechanical models as constitutive models for each ply. In these models, a full three-dimensional stress state is considered. Intralaminar and interlaminar damage can be introduced separately together with the complex interaction between them. At the macroscale level, the composite structural component will be carried out using shell elements which is very efficient from the numerical viewpoint and ideal for analysing large structures $[15,16]$. The basic idea is to treat the laminate as a homogeneous material whose mechanical properties are provided by the mesoscale model. The stiffness constants of the laminate are easily obtained using laminate theory while the onset of damage is provided by a failure envelope in the stress space. The failure envelope can be obtained by mesoscale modelling of the laminate under uniaxial and multiaxial stress states. 
Multiscale modelling is expected to have a large impact on the efficient design, testing and certification of composite structures in the aerospace/automotive industries because it opens the door to the industrial implementation of virtual design and virtual testing tools. The influence of the properties of the constituents and of their behaviour, which are a function of cure kinetics and material conditioning, on the mechanical performance distribution of composite materials can be easily and rapidly assessed, which is both time-saving and economical $[15,16]$.

\subsection{Micromechanical model}

\subsubsection{Constitutive law}

Carbon fibres are modelled as orthotropic solids considering thermal expansion in longitudinal and transverse directions. The polymer matrix of the composite material is modelled as an isotropic linear and elastic solid with an Extended Drucker-Prager model including a damage variable. The Extended Drucker-Prager yield criterion is a pressure-dependent model for determining whether a material has failed or undergone plastic yielding [18,

19]. This enables the RVE to capture the damage behaviour of the polymer under tension, compression and shear loading. The yield function is defined in terms of the $I_{1}$ and $J_{2}$ invariants of the stress tensor as,

$$
\Phi\left(I_{1}, J_{2}, \sigma_{I}, \beta, \alpha\right)=\frac{1}{1-\alpha}\left(\sqrt{3 J_{2}}+\alpha I_{1}+B\left\langle\sigma_{I}\right\rangle\right)-\sigma_{m y c}=0
$$

where $I_{1}$ stands for the first invariant of the stress tensor, $J_{2}$ is the second invariant of the deviatoric stress tensor, $\alpha$ is the pressure-sensitivity parameter of the Drucker-Prager yield criterion, $\sigma_{I}$ is the maximum principal stress, $\langle\quad\rangle$ is the Macaulay operator (returning the argument if positive and zero otherwise) and $B$ is a function of the tensile and compressive yield stresses, $\sigma_{m y t}$ and $\sigma_{m y c}$, respectively, defined as

$$
B=\frac{\sigma_{m y t}}{\sigma_{m y c}}(1-\alpha)-(1+\alpha)
$$

Where $\alpha$ can be expressed in terms of the internal friction angle of the material $(\beta)$ according to $\tan \beta=3 \alpha$.

The internal friction angle controls the hydrostatic pressure dependence of the plastic behaviour of the material.

Under compression, the matrix is assumed to behave as a perfectly plastic solid, without strain hardening. Thus, the compression yield stress, $\sigma_{m y c}$, has the same value as the compressive strength $Y_{c}$. Under tension, damage is initiated at $\sigma_{m y t}$, and the softening behaviour after the onset of damage is defined by a linear cohesive law, 
characterized by a single normalized scalar damage variable, to ensure the correct energy dissipation of the matrix, $\mathcal{G}_{m}$ (as shown in Figure 4a). Under shear loading, the matrix is modelled as elastic-plastic material with perfectly plastic post yielding behaviour. Both small and finite deformation theory were considered to investigate the effects of fibre rotation in the microscale level.

An experimental micromechanics approach, in the following section, was developed to determine the key properties, including the elastic modulus, $E_{m}$, the compression yield limit, $\sigma_{m y c}$, and the internal friction angle, $\beta$, of the matrix, by means of indentation. The fibre/matrix interface is modelling using cohesive surfaces, based on a traction-separation law. It enables the prediction of cohesive damage and the effect of friction occurring after fibre/matrix debonding. More detail about the cohesive zone model is given in the section 2.3.

\subsubsection{Model set-up}

In order to understand the role of fibre/matrix interfacial properties on the intralaminar failure behaviour, a computational micromechanical model based on a statistically representative volume element (RVE) was established. Several RVEs were generated such that the detailed microstructure information of fibre diameter distribution, volume fraction (60\%), fibre clusters and resin pockets are representative of the real unidirectional lamina. The input material parameters are summarised in Table 1 and Table 2 [20,21]. The interface fracture energy in mode I, $\mathcal{G}_{I C}$ could not be measured experimentally but it is assumed to be in the range of $2-5 \mathrm{~J} / \mathrm{m}^{2}$. Similar values were used by other authors and reported in the literature $[12,22,23]$. In addition, due to the lack of experimental data, the interface fracture energies in the shear modes were set equal to the matrix cracking fracture energy, $\mathcal{G}_{I I c}=100 \mathrm{~J} / \mathrm{m}^{2}$, a value similar to the one used [12]. A sensitivity study of these values indicates they only affect material behaviour in the damage propagation regime slightly, given in Section 5.1.

The RVEs were also able to account for the development of residual stresses in the material, prior to mechanical loading, arising from the temperature change from the curing temperature of $180{ }^{\circ} \mathrm{C}$ down to room temperature $20{ }^{\circ} \mathrm{C}$. The periodic RVE (as shown in Figure 2) was discretized using wedge and brick finite elements for fibres and matrix, with full Gauss integration (C3D6 and C3D8), respectively. Typically, each RVE contains approximately 20,000 elements representing a discretization fine enough to capture the large stress gradients between neighbouring fibres. Node positions on opposite faces of the RVE are identical to apply periodic boundary conditions (PBC) [12], 


$$
\left\{\begin{array}{lc}
\vec{u}(0, Y, Z)-\vec{u}\left(\boldsymbol{w}_{\mathbf{0}}, Y, Z\right)=\vec{U}_{X}, & \text { Master }-X \\
\vec{u}(X, 0, Z)-\vec{u}\left(X, \boldsymbol{L}_{\mathbf{0}}, Z\right)=\vec{U}_{Y}, & \text { Master }-Y \\
\vec{u}(X, 0, Z)-\vec{u}\left(X, Y, \boldsymbol{H}_{\mathbf{0}}\right)=\vec{U}_{Z}, & \text { Master }-Z
\end{array}\right.
$$

where $X, Y, Z$ are the coordinates axis, and $\vec{U}_{i}$ is the displacement of the master node $\mathrm{i}$ (with $i=X, Y, Z$ ). As a result, three master nodes are defined on the three-dimensional unit cell: Master-X $\left(w_{0}, 0,0\right)$, Master-Y $\left(0, L_{0}, 0\right)$ and Master-Z $\left(0,0, H_{0}\right)$. In this work, $L_{0}=H_{0}=58 \mu \mathrm{m}$ and $w_{0}=0.6 \mu \mathrm{m}$. Transverse tension and transverse compression is carried out with $\vec{U}_{X}=(0, \pm \delta, 0)$. Shear parallel to the fibres $\left(\tau_{X Z}\right)$ or shear perpendicular to the fibres $\left(\tau_{Y Z}\right)$ can be applied with $\vec{U}_{X}=(\delta, 0,0)$ or $\vec{U}_{Z}=(0,0, \delta)$ respectively. The displacement and reaction force of these master nodes were used to determine the stress-strain curves under shear loads and corresponding material stiffness/strength properties. Simulations were then implemented with ABAQUS /Standard 6.14 based on finite deformations theory [24].

\subsection{Mesoscale model}

\subsubsection{Constitutive law}

A homogenized mesoscale model considering both intralaminar and interlaminar damage is used to capture failure behaviour of short-beam bending tests. The material is defined as a homogenous, linear orthotropic solid. The effective stresses $\tilde{\sigma}=\tilde{C} \varepsilon$ are defined as stresses transmitted across the intact part of the cross-section in a Representative Volume Element (RVE),

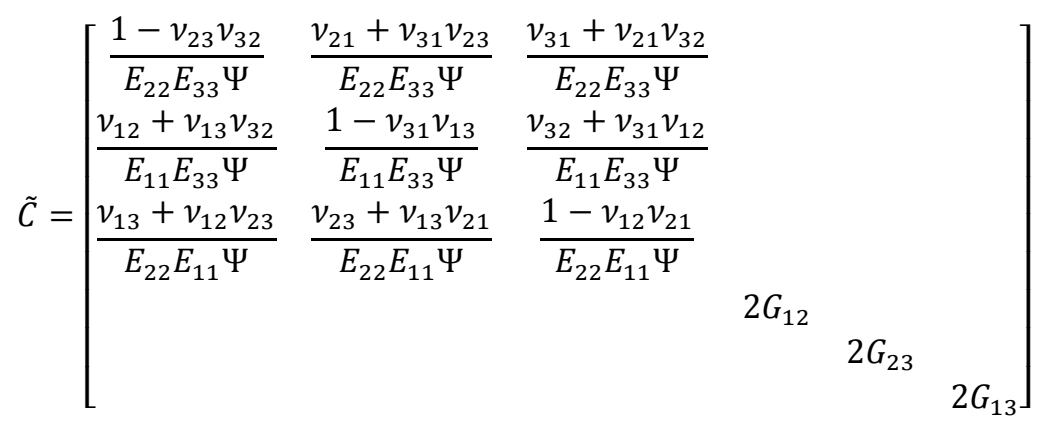

and $\Psi=\frac{1-v_{12} v_{21}-v_{23} v_{32}-v_{31} v_{13}-2 v_{12} v_{23} v_{31}}{E_{11} E_{22} E_{33}}$

Under shear loading, the fibres rotate towards the loading axis as the shear strain increases during tests, resulting in strain hardening. Published results in the literature have confirmed that the 'pseudo strain hardening' behaviour of composite material under large deformation shear loading is essentially attributed to fibre rotation 
$[10,25]$. Fibre rotation is facilitated by the yielding of the matrix and pick up load in tension, leading to influences on the post-yielding behaviour of the composite material. In this work, the fibre rotation behaviour is successfully predicted by the micromechanical model based on finite deformation theory as shown in Figure 11d and Figure 12d. To establish a mesoscale model that includes the fibre rotation effect, the local material coordinates should be updated during analysis so as to account for the rotation of fibres due to shear deformation. The total rotation of materials should also be decomposed into rigid rotation and fibre rotation [16]. For simplicity, the fibre rotation effect in this mesoscale model is explicitly modelled using the predicted nonlinear stress-strain curves from the micromechanical model (illustrated in Figure 4b). The stress-strain relation is represented by an exponential model,

$$
\tau\left(\gamma_{i j}\right)=\tau_{i j}^{Y}\left[\exp \left(c_{1} \gamma_{i j}\right)-\exp \left(c_{2} \gamma_{i j}\right)\right]
$$

where $\tau_{i j}^{Y}$ is the initial yield strength, determined by the $2 \%$ offset strain point, $c_{1}$ is a strain hardening coefficient and $c_{2}$ controls the initial shear modulus and elastic-plastic transition region. The non-linear coefficients, $c_{1(2)}$, are calibrated against the stress-strain data given by the micromechanical model. The non-linear shear strain, $\gamma_{i j}$, is decomposed as the sum of an elastic and inelastic component,

$$
\gamma_{i j}=\gamma_{i j, e l}+\gamma_{i j, i n} \quad i \neq j
$$

A strain-based damage initiation function is used to model the material response in the longitudinal direction. The failure initiation criterion, based on Puck and Schürmann's [26] and Catalanotti et al. [27], was used for predicting matrix damage behaviour. A brief summary of fibre-dominated and matrix-dominated failure criteria are given below. Full details of the criteria may be found in $[1,10,28]$ and are not repeated here for brevity,

Fibre-dominated

$$
\begin{aligned}
& \varepsilon_{11}>0, F_{11}^{T}\left(\varepsilon_{11}\right)=\left(\frac{\varepsilon_{11}}{\varepsilon_{11}^{O T}}\right)^{2} \geq 1 \\
& \varepsilon_{11}<0, F_{11}^{C}\left(\varepsilon_{11}\right)=\left(\frac{\varepsilon_{11}}{\varepsilon_{11}^{O C}}\right)^{2} \geq 1
\end{aligned}
$$

Matrix-dominated

$$
\begin{gathered}
\sigma_{N N} \leq 0, F(\theta)=\left(\frac{\sigma_{L N}}{s_{12}-\mu_{L N} \sigma_{N N}}\right)^{2}+\left(\frac{\sigma_{N T}}{s_{23}-\mu_{N T} \sigma_{N N}}\right)^{2} \\
\sigma_{N N}>0, F(\theta)=\left(\frac{\sigma_{N N}}{s_{23}}\right)^{2}+\left(\frac{\sigma_{L N}}{s_{12}}\right)^{2}+\left(\frac{\sigma_{N T}}{s_{23}}\right)^{2}+\lambda\left(\frac{\sigma_{N N}}{s_{23}}\right)\left(\frac{\sigma_{L N}}{s_{12}}\right)^{2}+\kappa\left(\frac{\sigma_{N N}}{S_{23}}\right)
\end{gathered}
$$


where $F_{11}^{T}$ and $F_{11}^{C}$ are the failure indices for tensile and compressive loading, and the failure initiation strains ( $\varepsilon_{11}^{O T}$ and $\varepsilon_{11}^{O C}$ for tension and compression, respectively) are determined by the strengths in the respective directions, i.e. $\varepsilon_{11}^{O T}=X^{T} / E_{11}^{0}$ etc. The stress tensor $\sigma_{L N T}=[T(\theta)] \sigma_{123}[T(\theta)]^{T}$ on the fracture plane was rotated using the standard transformation matrix $T(\theta)$, from the material coordinate system (123) to the fracture plane coordinate system (LNT), where $\theta$ is defined as the angle of the potential fracture plane. Parameters $\kappa$ and $\lambda$ are given by $\kappa=S_{23}^{2}-\left(Y_{T}\right)^{2} / S_{23} Y_{T}$, and $\lambda=2 \mu_{L N} S_{23} / S_{12}-\kappa$, where $S_{12}$ and $S_{23}$ are the shear strengths. The transverse friction coefficients $\mu_{N T}$ and $\mu_{L N}$, defined in [29], are based on Mohr-Coulom theory where $\mu_{N T}=$ $-1 / \tan \left(2 \theta_{f}\right), S_{23}=Y_{C} / 2 \tan \left(\theta_{f}\right)$ and $\mu_{L N}=\mu_{N T} S_{12} / S_{23}, Y_{C}$ and $Y_{T}$ are the transverse compressive strength and transverse tensile strength, respectively. The fracture plane orientation, $\theta_{f}$, is typically found to be around $53^{\circ}$ for unidirectional composites under uniaxial transverse compressive loading [29]. For a general 3D load state, the orientation is not known a priori and is determined by the angle which maximizes the matrix dominated failure criteria functions. Brent's algorithm [30] was used for this purpose which combines a golden section search with parabolic interpolation.

The damage tensor is a function of three monotonically increasing damage variables, bound by 0 (no damage) and 1 (complete failure), each one relating to a form of damage mode under a different loading state. $d_{11}^{T}$ refers to tensile damage in the fibre direction, $d_{11}^{C}$ refers to compressive damage in the fibre direction and $d_{\text {mat }}$ refers to matrix cracking due to a combination of transverse tension/compression and shear loading (shown in Figure 4c). The damage parameter associated with loading in the longitudinal direction is given by,

$$
d_{11}^{T(C)}\left(\varepsilon_{11}\right)=\frac{\varepsilon_{11}^{F T(C)}}{\varepsilon_{11}^{F T(C)}-\varepsilon_{11}^{O T(C)}}\left(1-\frac{\varepsilon_{11}^{O T(C)}}{\varepsilon_{11}^{T(C)}}\right), \varepsilon_{11}^{T(C)}>\varepsilon_{11}^{O T(C)}
$$

where the failure strains, $\varepsilon_{11}^{F T(C)}$, at which net-section fracture across the element occurs, is determined by the critical energy release rates $\Gamma_{11}^{T(C)}$, and longitudinal tensile/compressive strength, $X_{T(C)}$, given by,

$$
\varepsilon_{11}^{F T(C)}=2 \Gamma_{11}^{T(C)} / X_{T(C)} l_{f i b}
$$

where $l_{f i b}$ is the characteristic length. Mesh objectivity of the model was achieved by employing the crack-band model of Bažant and Oh [31].The characteristic length associated with the longitudinal direction is determined by $l_{f i b}=V / A$, where $V$ is the element volume and $A$ is calculated using an approach proposed in [1]. 
The overall damage progression for matrix damage is based on the mixed-mode loading state shown in Figure $4 \mathrm{~d}$. Once damage initiates, the normal and shear stresses on the fracture plane are recorded and a resultant stress $\sigma_{r}=$ $\sqrt{\left\langle\sigma_{N N}\right\rangle^{2}+\left(\sigma_{N T}\right)^{2}+\left(\sigma_{N L}\right)^{2}}$ is calculated. The degradation of the combined stress, $\sigma_{r}$, on the fracture plane was defined using a single damage parameter, $d_{\text {mat }}$, Eq. (13).

$$
d_{m a t}=\frac{\varepsilon_{r}^{f}-\varepsilon_{r, i n}^{0}}{\varepsilon_{r}^{f}-\varepsilon_{r}^{0}}\left(1-\frac{\varepsilon_{r}^{0}-\varepsilon_{r}}{\varepsilon_{r}-\varepsilon_{r, i n}^{0}}\right)
$$

The matrix-dominated damage propagation is governed by the critical mixed-mode strain energy release rate, $\Gamma_{r}^{c}$, which is a function of the stresses $\left(\sigma_{N N}, \tau_{N L}, \tau_{N T}\right)$, the corresponding critical strain energy release rate $\left(\Gamma_{22}^{C}, \Gamma_{12}^{c}, \Gamma_{23}^{c}\right)$, and $l^{2}$-norm of the stress vector on the fracture plane $\left(\sigma_{r}\right)$. The critical mixed-mode strain energy release rate, $\Gamma_{r}^{c}$, is then given by Eq. (14).

$$
\Gamma_{r}^{C}=\Gamma_{22}^{C}\left(\frac{\sigma_{N N}^{0}}{\sigma_{r}^{0}}\right)^{2}+\Gamma_{12}^{C}\left(\frac{\tau_{N L}^{0}}{\sigma_{r}^{0}}\right)^{2}+\Gamma_{23}^{C}\left(\frac{\tau_{N T}^{0}}{\sigma_{r}^{0}}\right)^{2}
$$

\subsubsection{Model set-up}

Unidirectional $\left[0^{\circ}\right]_{10}$ composite specimens were created in ABAQUS/Explicit 6.14, as shown Figure 3. Elastic properties were calculated based on Chamis's rule of mixtures accounting for the intraply, interplay void content and resin-rich region (Table 3) [32]. Other material properties summarized in Table 4 and Table 5 were used to model the short beam bending behaviour [20]. The geometry was meshed (C3D8R) using an element size of 0.25 $\mathrm{mm} \times 0.25 \mathrm{~mm}$ within the lamina plane and $0.05 \mathrm{~mm}$ in the through-thickness direction. The lamina thickness, considering the void content and thick resin layer is $0.2 \mathrm{~mm}$. To suppress spurious energy modes, an enhanced stiffness-based hourglass and distortion control were employed. Instead of introducing the voids and thick layer of matrix into the finite element model, the interlaminar properties between plies were simplified by defining it as surface-based cohesive behaviour with the interlaminar shear strength $\tau_{I L S S}$ measured from experiment. A general contact algorithm was utilised to generate a contact force between contact surfaces. 'Hard' contact conditions were defined between the platen and the plies as well as adjacent plies. The platen was modelled as an analytical rigid surface. The friction coefficients of ply-to-ply and ply-to-indenter contact were set to 0.4 [12] and 0.2 respectively [10]. BK-law mixed-mode ratio $\eta=2$ and a penalty interface stiffness $k=1 \times$ $10^{5} \mathrm{~N} / \mathrm{mm}^{3}$ were chosen. 


\subsection{Cohesive zone model}

The surface-based cohesive behaviour [33] was used to capture both fibre/matrix debonding and interplay delamination using a bilinear traction-separation relationship. This approach is a convenient means to model the cohesive connections without the need to define cohesive elements and tie constraints. Contact separations are the relative displacements between the nodes on the slave surface and their corresponding projection points on the master surface along the contact normal and shear directions. Traction stresses are defined as the cohesive forces acting along the contact normal and shear directions divided by the current area at each contact point. Failure initiation was governed by a quadratic stress criterion,

$$
\left(\frac{t_{1}}{t_{1}^{0}}\right)^{2}+\left(\frac{t_{2}}{t_{2}^{0}}\right)^{2}+\left(\frac{\left\langle t_{3}\right\rangle}{t_{3}^{0}}\right)^{2} \leq 1
$$

where $t_{i}(i=1,2,3)$ are the traction stress vectors in the in-plane (1,2) and normal (3) directions, respectively, and $t_{i}^{0}$ are the corresponding maximum stresses associated with each direction, $t_{s h}^{0}=\sqrt{\left(t_{1}^{0}\right)^{2}+\left(t_{2}^{0}\right)^{2}}$ is the resultant shear stress. The corresponding separations are denoted by $\delta_{i}(i=1,2,3)$, where the resultant planar shear separation is defined by $\delta_{s h}^{0}=\sqrt{\left(\delta_{1}^{0}\right)^{2}+\left(\delta_{2}^{0}\right)^{2}}$ and $\delta_{3}=\delta_{\text {norm }}$ is the normal separation of the cohesive surfaces. Delamination was propagated using a mixed-mode relationship proposed by Benzeggagh and Kenane (B-K propagation criterion) [34],

$$
G_{C}=G_{I c}+\left(G_{I I C}-G_{I c}\right) \mathrm{B}^{\eta}
$$

where $G_{c}$ is the mixed-mode fracture toughness, $B$ is the local mixed-mode ratio defined as $B=G_{\text {shear }} /\left(G_{I}+\right.$ $\left.G_{\text {shear }}\right) \cdot \eta$ is the mixed-mode interaction. The normal strength is assumed equal to $t_{3}^{0}=2 / 3 t_{\text {sh }}^{0}$ based on the experimental results [35]. The interlaminar fracture toughness considering void content are using $G_{I c, I I c}^{\text {void }}=$ $G_{I c, I I c}\left[\mathbf{1}-\left(\frac{\mathbf{4 f} \text { void }}{\pi}\right)^{\mathbf{1} / \mathbf{2}}\right][36]$ as a reasonable approximation.

\section{Material and methods}

\subsection{Autoclave manufacturing}

In this study, fibre reinforced composite laminates were manufactured from unidirectional carbon fibre (T800) reinforced/epoxy (CYCOM X850) prepreg [37]. Pre-impregnated sheets were supplied by Commercial Aircraft 
Corporation of China, Ltd with a fibre volume fraction of $65 \%$ and areal density of $190 \mathrm{~g} / \mathrm{m}^{2}$. T800/X850 used a thermoplastic toughened epoxy to improve the delamination toughness, which includes a thermoplastic toughened epoxy interlayer of about 25 to $30 \mu \mathrm{m}$ thickness between layers. Eight unidirectional [0] $]_{10}$ composite laminates were fabricated in an autoclave with different values of applied pressure: $0.0,0.1,0.2,0.3,0.4,0.5,0.6$ and 0.8 MPa. Laminates were heated at a constant rate of $1.5^{\circ} \mathrm{C} / \mathrm{min}$ to $180{ }^{\circ} \mathrm{C}$ and held for $150 \mathrm{~min}$ at this temperature. Afterwards, they were cooled down to room temperature $\left(20^{\circ} \mathrm{C}\right)$ under the same pressure. The dimensions of the laminates were $200 \mathrm{~mm}$ (length) $\times 200 \mathrm{~mm}$ (width) $\times 2 \mathrm{~mm}$ (thickness), and the final cured thickness of the composite laminates was $2.0 \pm 0.2 \mathrm{~mm}$.

\subsection{Mechanical characterization}

Matrix properties within the composite were measured by means of nanoidentation [13] while push-in tests of single fibres within the laminate were used to determine the interface strength $[38,39]$. Push in tests were preferred instead of single fibre fragmentation tests [40,41] or microbond tests [42] to measure the fibre-matrix interface properties because they are influenced by the fibre packing density and the degree of matrix cure, which are accounted for in the push-in tests. The interlaminar shear strength was determined by means of a short-beam three point bending test [43] while optical and scanning electron microscopy were used to assess the void content and fracture mechanisms, respectively.

\subsubsection{Fibre/matrix interfacial properties}

The unidirectional laminates, consolidated at different pressures, were cut with a precision diamond saw to nominal dimensions of $10 \mathrm{~mm} \times 10 \mathrm{~mm} \times 2 \mathrm{~mm}$. Samples were embedded in epoxy resin to facilitate handling during polishing. Surfaces perpendicular to the fibres were polished with silicon carbide papers of 600, 1000, 2000, and 4000 grade, and polished with diamond pastes of $0.3 \mu \mathrm{m}$ and $0.1 \mu \mathrm{m}$, followed by ultrasonic cleaning. The samples were inspected with an optical microscope to find the position of typical hexagonal fibre packing patterns. Afterwards, they were moved beneath the low-load indenter probe of a Hysitron TI 950 triboindenter. The in-situ images obtained by raster scanning with the indenter probe over the sample surface led to the precise location of the fibre under the flat punch. Push-in tests of fibres were carried out with the high load indenter probe (maximum load of $950 \mathrm{mN}$ ) with a diamond flat punch of $5 \mu \mathrm{m}$ in diameter. Push-in tests were performed under displacement control at $40 \mathrm{~nm} / \mathrm{s}$ up to a maximum displacement of $1200 \mathrm{~nm}$ followed by unloading to the 
initial position. More than 15 fibre tests were carried out for each laminate. The fibres tested were surrounded by six nearest neighbours following a hexagonal close packing distribution.

In this work, the interfacial shear strength (IFSS), $\tau_{I F S S}$, was determined from the load-displacement curves provided by the nanoindenter following the methodology developed by Rodríguez et al [39]. The loaddisplacement curve $(P-u)$ presents an $S$ shape, and the initial region corresponds to an imperfect contact between the indenter and the fibre. This is followed by a linear region (with slope $\mathrm{S}_{0}$ ) due to the elastic deformation of the fibre and the matrix, which is followed by a non-linear region due to the onset of interface failure. The IFSS can be determined from the critical load $P_{c}$ at the onset of interface failure through the shearlag model $[44,45]$. This definition provides a good indication of the critical load at the initiation of debonding,

$$
\tau_{S L}=\frac{n P_{c}}{2 \pi r^{2}}
$$

Where $n$ is a parameter that depends on the elastic properties of the fibres and the matrix and local fibre patterns and volume fraction. $n$ can be determined from the slope of the $P-u$ curve in the linear region, $\mathrm{S}_{0}$, according to:

$$
n=\frac{\mathrm{S}_{0}}{\pi r E_{f}}
$$

Where $E_{f}$ is the longitudinal elastic modulus of the fibre modulus.

\subsubsection{Matrix properties}

The influence of cure pressure on the modulus of the resin was determined by performing nanoindentation tests in resin pockets identified on the polished cross-section of the composite materials (Thick layer of resin between adjacent plies). A Berkovich indenter was used to perform cyclic loading-unloading tests and to determine the elastic modulus as a function of indentation depth. Based on the Oliver and Pharr method [46], the reduced indentation modulus, $E_{r}$, is given by:

$$
E_{r}=\frac{S}{2 \beta} \sqrt{\frac{\pi}{A\left(h_{c}\right)}}
$$

where $S$ is the unloading stiffness, $A\left(h_{c}\right)$ is the contact area of indentation at the contact depth $h_{c}$ and $\beta$ is a geometrical parameter that is taken as $\beta=1.034$ for Berkovich indenters. The contact depth $h_{c}$ is given by: 


$$
h_{c}=h-0.75 \frac{P}{S}
$$

where $P$ and $h$ are the indentation load and depth, respectively. The elastic modulus of the matrix $E_{m}$ was determined from the reduced modulus $E_{r}$ :

$$
\frac{1}{E_{r}}=\frac{1-v_{i}}{E_{i}}+\frac{1-v_{m}}{E_{m}}
$$

where $\mathrm{E}_{i}=1141 \mathrm{GPa}$ and $v_{i}=0.07$ [46] are the elastic modulus and Poisson ratio of the diamond indenter, respectively and the Poisson's ratio of the matrix $v_{\mathrm{m}}=0.35[20,21]$. Typical values found in the literature for epoxy resins $\mathcal{G}_{m}$ are in the range of $40 \mathrm{~J} / \mathrm{m}^{2}$ and $400 \mathrm{~J} / \mathrm{m}^{2}$. Matrix toughness for X850 is assumed as $\mathcal{G}_{m}=100$ $\mathrm{J} / \mathrm{m}^{2}$.

\subsubsection{Interlaminar shear strength}

The interlaminar shear strength (ILSS) was determined according to the ASTM standard D2344/D2344M [43] using the short-beam three point bend test. The specimens were cut by diamond saw to a nominal dimensional of $20 \mathrm{~mm} \times 10 \mathrm{~mm}$ (length $\times$ width) and the tests were carried out in a CMT5105 tensile testing machine (produced by Sansi Taijie Co., Ltd., China). Three tests were performed for each laminate under displacement control at a constant crosshead rate of $1 \mathrm{~mm} / \mathrm{min}$. The radius of loading roller and the support roller were $5 \mathrm{~mm}$ and $2 \mathrm{~mm}$ respectively. The span length between support rollers was $14.5 \mathrm{~mm}$. The interlaminar shear strength of the composite samples was determined according to,

$$
\tau_{I L S S}=\frac{3}{4} \frac{P_{\max }}{b h}
$$

where $P_{\text {max }}$ was the maximum load during the test and $b$ and $h$, the sample width and thickness, respectively.

\subsubsection{Microstructural characterization}

The samples were polished following the procedure detailed above for the optical microscopy inspection. Void area fraction was measured from the optical microscopy images using an image analysis program. Cross-sections of short beam bending test samples were polished and inspected using optical microscopy (perpendicular to fibre orientation, YZ plane in Figure 5), while their facture surfaces of the broken samples (parallel to fibre orientation, XY plane in Figure 5) were examined by scanning electron microscopy (SEM) to investigate the interlaminar failure mechanisms. 


\section{Experimental results}

\subsection{Void content}

Optical micrographs of the cross-section of the laminates manufactured under different autoclave pressure are depicted in Figure 5. Interlaminar resin-rich areas can be readily observed in the X850 prepreg laminates, resulting from the inclusion of a thermoplastic interlayer to improve delamination toughness and compressionafter-impact strength $[47,48]$. The prepreg product included a resin rich surface containing fine, tough thermoplastic particles. Since these thermoplastic particles have a melting point at or below the curing temperature, they melted during curing, making them almost invisible in the final cured laminate. Figure 5 shows that the porosity decreased as the cure pressure increased and more details may be found in [49]. Most of the voids in the laminates processed under low pressure $(<0.4 \mathrm{MPa})$ were found in the resin rich region between plies. These voids normally proceed from entrapped air bubbles during lay-up which were not evacuated during autoclave curing [36]. In addition, smaller voids were found within the plies. X-ray microtomography analyses showed that the intraply voids were elongated with the longer axis parallel to the fibre direction and originated from bubbles in the pre-preg as well as from volatiles arising from the resin during cure $[36,50,51]$. Cure pressures in the range from $0.4 \mathrm{MPa}$ to $0.6 \mathrm{MPa}$ led to laminates with negligible porosity, but the porosity increased rapidly as the cure pressure was reduced below $0.4 \mathrm{MPa}$. Moreover, reducing the cure pressure led to the formation of wrinkles in the laminate, particularly in the laminates consolidated with $0.1 \mathrm{MPa}$ or without pressure. Intraply void content and interplay void content are summarized in Table 3, and were used to calculate the effective longitudinal modulus of composite laminates for mesoscale finite element modelling.

\subsection{Matrix properties}

The imprint due to a Berkovich tip in a resin-rich pocket is shown in Figure 6a. The elastic modulus was determined for different indentation depths following the procedure indicated above and the evolution of the elastic modulus with the indentation depth is plotted in Figure 6b. The measured modulus deceased with indentation depth for small indentation depths (a behaviour that it is well established, see [46]) but quickly reached a plateau for indentation depths larger than $1 \mu \mathrm{m}$. The elastic modulus was $\approx 4.7 \mathrm{GPa}$, independently of cure pressure, and it was concluded that the matrix modulus was not influenced by the curing pressure. The value of matrix modulus is close to the experimental value provided by the supplier $(E=4.56 \sim 4.75 \mathrm{GPa})$ [37]. 


\subsection{Fibre/matrix interfacial shear strength}

Push-in tests were always carried out in the centre of fibres surrounded by six fibres in a hexagonal pattern, as shown in Figure 7a. Interface fracture developed and the fibre was pushed in (Figure 7b). Representative loaddisplacement curves of fibres pushed in from laminates cured under different pressure are plotted in Figure 8a. The initial elastic stiffness was independent of the cure pressure but differences were found in the onset of the non-linear region and the higher the cure pressure the higher the load required to push in the fibre. The IFSS was calculated from these curves following the methodology developed by Rodríguez et al. [39]. The critical load, $P_{c}$, was determined from the intersection of the $P-u$ curve (Figure $8 \mathrm{~b}$ ) with a straight line that connects two points of the $P-u$ curve determined from two parallel lines with the initial stiffness $S_{0}$ drawn with offset displacements of $2 \%$ and $10 \%$. The evolution of the IFSS with cure pressure is plotted in Figure 9a. IFSS increases significantly from $56 \mathrm{MPa}$ under cure pressure $0 \mathrm{MPa}$ to $66 \mathrm{MPa}$ under cure pressure of $0.2 \mathrm{MPa}$. Since all the push-in tests are conducted in a typical hexagonal pattern without any visible voids or defects, it can be concluded that the increasing interfacial strength (IFSS) is not affected by the void content. The dramatic enhancement of IFSS (18.34\%) is mainly attributed to the improved contact between fibre and matrix. When cure pressure increases from 0.2 MPa to 0.6 MPa, the value of IFSS reaches $76 \mathrm{MPa}$ due to a better interface adhesion between fibre and matrix under higher pressure. The mechanisms responsible for the higher fibre/matrix adhesion of the specimens cured at high pressure in the autoclave are not clear, although enhanced lateral physical adsorption or mechanical interlocking on a rough surface (pressure sensitive adhesion) may play a role $[52,53]$. Higher fibre/matrix adhesion results in the enhanced capability to transfer loads from the matrix to fibres through the stronger interface.

\subsection{Interlaminar shear strength}

The evolution of the interlaminar shear strength (ILSS) as a function of the cure pressure is plotted in Figure 9b. This curve shows that the ILSS increased rapidly with the autoclave pressure up to $0.4 \mathrm{MPa}$. Afterwards, it was independent of the autoclave pressure. Figure 5 shows the post failure surface of the composite laminates under short-beam bending tests using different autoclave pressure (0.2 $\mathrm{MPa}$ and $0.6 \mathrm{MPa})$. The crack in the materials consolidated under $0.2 \mathrm{MPa}$ mainly propagated along the void rich area either in the interlaminar resin area or in the intraply by connecting the voids. This confirms that the interlaminar shear strength was mainly controlled by the void content when extensive voids exist. Under a higher cure pressure (0.6MPa), voids vanish and cracks 
initiated and propagated in the intralaminar area through failure of the fibre/matrix interface. Therefore, ILSS failure modes in low void content composite laminates are dominated by fibre/matrix interface failure. Extensive delamination occurs in the middle plies (between ply 5 and ply 6 ). This is caused by the highest shear stress in the neutral plane under three-point bending.

The fracture surfaces of the samples tested in three-point bending to measure the ILSS were analysed by a scanning electron microscope and representative micrographs can be found in Figure 10. The typical resin cusp structures (platelets inclined on the surface), indicative of fracture by shear along the fibre direction, can be found in all micrographs, although the number increases with the autoclave pressure. Cusps were formed as successive, parallel microcracks initiated by shear in the epoxy matrix along the main crack propagation direction.

In the case of the laminate cured without pressure (Figure 10a), the fibre surface was smooth, indicating poor adhesion between matrix and fibres, and some fibres are even inclined and rotated due to the lack of support from matrix. In addition, resin rich pockets and voids are observed. These features demonstrate that impregnation of resin is poor and inhomogeneous in the absence of pressure, leading to low values of fibre/matrix interfacial strength and of the laminate interlaminar strength. As the cure pressure increased (Figure $10 \mathrm{~b}$ and Figure 10c), cusp structures became dominant and voids disappeared, indicating that the infiltration process was adequate.

Increasing pressure leads to more resin cusps areas. Upon the application of pressure, most of the load was transferred through a continuous skeleton of fibre-rich regions. The higher pressure in these regions led to the migration of resin as well as voids. These SEM images confirm that the cure pressure drives the resin flow to impregnate the fibre. In the range of $0 \mathrm{MPa}$ and $0.3 \mathrm{MPa}$, when extensive voids are distributed, ILSS is mainly controlled by the void content which induces localized stress concentrations. However, when cure pressure reaches $0.4 \mathrm{MPa}$ or above, ILSS is dominated by fibre/matrix interface failure.

The higher cure pressure will lead to better impregnation performance and hence facilitated the coalescence and elimination of voids. At the same time, it will improve the adhesion between fibre and matrix and corresponding IFSS and interlaminar strength (ILSS). There is no direct relationship between IFSS and ILSS (Table 3). The interlaminar shear strength was mainly controlled by the void content under low cure pressure, while when cure pressure reached 0.4 MPa or above, failure modes in ILSS were dominated by fibre/matrix interface failure. It is 
not surprising to find that composite laminates with negligible void content and good mechanical properties at the micro and macro level could be obtained with autoclave pressures above $0.4 \mathrm{MPa}$ (current standard cure pressure in aerospace industry is $0.6 \mathrm{MPa}$ ).

\section{Computational modelling results}

\subsection{Micromechanical model}

Material properties from the material supplier and characterised by the nano-indentation tests were used as input material parameters (summarised in Table 1 and Table 2). Figure 11 and Figure 12 show the predicted failure modes and stress-strain curves of the RVE under transverse tension, transverse compression, shear perpendicular to fibre and shear parallel to fibre. Interfacial properties under different cure pressures were used as input parameters to investigate the effect of interfacial shear strength on the ply-level intralaminar behaviour. Damage due to longitudinal tensile/compressive stresses is not modelled in this work, as this has been previously reported [54].

Under pure transverse tension loading (Figure 11a and Figure 12a), the damage process is mainly dominated by fibre/matrix interface debonding for all cure pressure conditions. Cracks start at the fibre cluster along the loading direction in those regions where the stress concentrations in the fibre/matrix interface are higher. After initiation of the interface failure, the matrix experienced severe plastic deformation, accumulating damage until ultimate failure of the matrix ligaments. The final failure of the RVE is a crack perpendicular to the loading axis. Stress-strain curves indicate that the intralaminar strength increased as the interfacial shear strength improved while the stiffness remained unchanged.

Under pure transverse compression (Figure 11b and Figure 12b), the final failure of the composite ply takes place by the development of matrix shear bands. Failure under pure transverse compression appears not to be initiated by interface debonding but directly by shear banding with an orientation of $\theta_{f}=53.5^{\circ}$, which is very close to published experimental data [29] and has been used by many CDM models based on Puck's failure criteria [26].

Under shear loading (Figure 12c to Figure 12f), the shear fracture initiates as interfacial debonding and evolves as a result of interactions between interfacial debonding and matrix plastic deformation. To accurately capture 
the non-linear behaviour under large deformation, large deformation theory that considering fibre rotation effect was used.

When transverse shear $\tau_{Y Z(23)}$ is applied in the $Y Z$ plane as shown in Figure 11c, failure is trigged by interface debonding. There are multiple initiation matrix cracking sites with orientation of $\theta_{f}=45^{\circ}$. As the crack propagated, plastic shear band deformations were formed. The stress-strain curves in Figure 12c show that the initial elastic behaviour is followed by a remarkable strain hardening behaviour, as matrix deformation is restricted by the fibre in the post-yielding regime.

If longitudinal shear $\tau_{X Z(13)}$ is applied in the $X Z$ plane, Figure $11 \mathrm{~d}$, the non-linear behaviour is dominated by matrix yielding, as the interface strength was higher than the matrix yield strength and the initial region of the stress-strain curves (Figure 12d) was not affected by interface debonding. Different behaviour was observed, depending on the shearing direction, parallel, $\tau_{X Z}^{\|}$, or perpendicular to the fibres, $\tau_{X Z}^{\perp}$, although the elastic behaviour and yield strength was almost identical. When shear loading was parallel to fibres, $\tau_{X Z}^{\|}$, a perfectplastic behaviour was observed for all these test cases as the matrix yield strength was lower than the interface shear strengths considered. When shear loading was applied perpendicular to the fibre, $\tau_{X Z}^{\perp}$, a remarkable strain hardening effect was attained. As the fibres rotated with matrix plastic yielding, they started to pick up load in tension when the strain, $\varepsilon>1 \%$. The combined effect of fibres and matrix give rise to the global strain hardening effect. In this study, the final stress-strain constitutive relationship and shear strength, $S_{13(12)}$, was approximated as the average of the values $\tau_{X Z}^{\|}$and $\tau_{X Z}^{\perp}$, as suggested by Totry [25].

A sensitivity study of the cohesive penalty stiffness, $K_{n n(s s, t t)}$, (Figure 12e) shows that penalty stiffness should be larger than $10^{4} \mathrm{~N} / \mathrm{mm}^{3}$ to ensure displacement continuity in the absence of interface damage while avoiding convergence difficulties due to an ill-conditioned stiffness matrix. Figure $12 \mathrm{f}$ indicates that the effect of the critical interface fracture energy on the material behaviour is limited unless very small value of $G_{I c(I I c)}$ are used, which will lead to premature failure.

All these predicted properties, including transverse tensile strength/stiffness, transverse compressive strength/stiffness and strength/stiffness are summarized in Table 4 . The reported numerical predictions are mean value of 5 random RVEs. They show good agreement with experimental results obtained under the 
manufacturer's recommended curing cycle. The predicted homogenized ply properties were then used as input parameters for a mesoscale model to predict the laminate behaviour under bending.

\subsection{Mesoscale model}

A homogenized mesoscale model which accounts for both intralaminar and interlaminar damage was used to predict the failure of short-beam bending tests. A numerical model that could predict interlaminar shear strength and fracture energy are still presenting significant challenge to researchers. Most existing mesoscale models [18] reply on measured interlaminar strength and fracture energy as they can be easily characterized using standard tests. In this mesoscale model, only the intralaminar material properties were predicted by the micromechanical model, while interlaminar properties where taken directly from experimental measured values. Interlaminar resin-rich regions, containing a large quantity of random voids, make it very difficult to predict interlaminar properties using a microscale model. It would be even more difficult to predict all these interlaminar properties under mode I, mode II and mixed-mode loading. Varandas et al [55] have shown that a virtual Transverse Crack Tension (TCT) specimen is able to predict mode II interlaminar fracture toughness for a void-free composite laminate. Gilabert et al. [56] presented a macro-micro FE model to model crack propagation in encapsulationbased self-healing materials. This method combined XFEM and cohesive surface behaviour which could be employed to model the fibre-bridging effect that contributes a higher propagation interlaminar fracture toughness. Inspired by these methods, a more detailed study for predicting interlaminar properties from a computational micromechanical model should be considered in future.

Three groups of predicted intralaminar material properties and measured interlaminar properties were used as the input parameters to understand the interaction between intralaminar and interlaminar damage in SSB tests (Table 4 and Table 5). The carbon fibre lamina and the resin rich layer were homogenized as a single ply. The nonlinear hardening effect was explicitly represented by an exponential model where the coefficients $c_{i}(i=1,2,3)$ were calibrated against the micromechanically predicted stress-strain curves (as the average of the stress-strain curves under shear loading of $\tau_{X Z}^{\|}$and $\left.\tau_{X Z}^{\perp}\right)$ [25].

Figure 13a shows the numerical and experimental load/displacement curves with three groups of interface properties. For the samples with very lower interfacial and matrix properties ( $0 \mathrm{MPa})$, the initial bending stiffness is very low due to the large extent of void content, which degraded the material stiffness significantly. Yielding of the matrix occurred at a load of $800 \mathrm{~N}$. This was followed by a marked non-linear shear behaviour 
with a constant hardening rate. The non-linear hardening behaviour is believed to be the combination effect of geometrical fibre rotation, matrix yielding and interlaminar delamination. As the matrix start to yield with perfect-plastic behaviour, fibre rotation was able to accommodate the shear strain and pick up the load in tension, leading to the global hardening effect. In the numerical simulation, the fibre rotation hardening effect is explicitly represented by an exponential function given in Eq.(5). This simplified method the enabled finite element model to capture the material shear response accurately. Figure $13 \mathrm{~b}$ indicated the presence of delamination in the non-linear region. Delamination failure was trigged after matrix yielding, because the interlaminar shear strength is slightly higher than the matrix yield strength. Delaminations were mainly localized underneath the loading point where high interlaminar shear stresses are concentrated. Figure 13c illustrates the permanent inelastic strain accumulated in the non-linear shear region, which is a good indicator of shear localization in the intralaminar region.

For the samples cured under higher pressure (0.2 $\mathrm{MPa}$ and $0.6 \mathrm{MPa})$, with most voids removed and better interlaminar and intralaminar properties achieved, the material becomes stiffer and stronger. The yielding strength and ultimate failure strength are also improved. Both of their post-yielding regimes showed a similar non-linear hardening behaviour, which again were caused by fibre rotation. Numerical results show very good correlation in stiffness, yield strength and non-linear hardening behaviour.

Numerically predicted intralaminar damage contours for the composite laminates are shown in Figure 14. The damage is mainly attributed to the combination of shear (parallel to fibre) and compression/tension (throughthickness) loading. Extensive damage was initiated and propagated in the laminate with poor interlaminar properties and intralaminar matrix strength (cured under $0 \mathrm{MPa}$ ). As the interlaminar properties and matrix strength were enhanced under higher curing pressure (0.2 $\mathrm{MPa}$ and $0.6 \mathrm{MPa})$, the extent of damage was reduced and localized to plies close to the middle plane where the shear stresses are highest. The SEM image in Figure $14 \mathrm{c}$ shows the intralaminar shear failure due to high shear loading, which is consistent with the micromechanical failure shown in Figure 11d. Model without considering fibre rotation can only capture the elastic part and peak load. The failure in the its plateau regime was dominated by interlaminar shear failure. Model with fibre rotation was able to capture non-linear behaviour, as mesoscale model explicitly considers this hardening behaviour in the constitutive model of matrix under shear loading. Simulation results considering fibre rotation effect achieved excellent agreement with experiment both quantitatively and qualitatively. 
The damage initiated in the composite laminates is mainly caused by competing intralaminar and interlaminar damage mechanisms. In these composite laminates cured under low pressure (0 MPa and 0.2 MPa), void contents dramatically knocked down the interlaminar shear strength. Delamination was the dominated failure mode. For laminates cured under 0.6 MPa, intralaminar matrix shear strengths are slightly lower than the interlaminar shear strength. This leads to extensive intralaminar damage rather than delamination. Final failure was eventually caused by the interaction of these two damage modes throughout the width of the specimen.

Local indentation underneath the loading roller or above the support rollers was also captured by this meso-scale model. This is attributed to the nonlinear shear formulation of the meso-scale intralaminar damage model. The shear strain was decomposed into elastic strain $\gamma_{e l}$ and inelastic strain $\gamma_{i n}$ components, the latter enabling the capture of permanent indentation.

It should also be mentioned that validation of the mesoscale model for impact and crush loading has been successfully conducted by the authors $[1,2,11]$. Extension to this multiscale modelling framework, where the composite laminates are homogenized as continuum shell elements for the modelling of large macroscale structures is not show in this paper, but is a natural extension to this work which would fit within current conventional modelling methods used in the aerospace industry.

\section{Conclusions}

A hierarchical bottom-up multiscale modelling approach is presented to explore the role of interfacial properties (fibre/matrix interface and interlaminar interface) on the intralaminar and interlaminar failure mechanisms in composite laminates. The influence of the autoclave curing pressure (from 0 to $0.8 \mathrm{MPa}$ ) on the microstructure and mechanical properties of unidirectional carbon-fibre reinforced epoxy composites was characterised. The microstructure (mainly void content and spatial distribution) and the mechanical properties of the matrix and fibre/matrix interface were measured, the latter by means of nanoindenation tests in matrix pockets and fibre push-in tests. These material parameters were used in the microscale model as input parameters to predict the intralaminar material behaviour (e.g. stiffness, non-linear hardening behaviour and strength). The macroscopic interlaminar shear strength was determined by means of three-point bend tests on short beams. Microscale predicted intralaminar properties and interlaminar shear strength values were imported into the mesoscale model to predict composite laminate behaviour. The main conclusion drawn from this work are as follows: 
- The cure pressure had a strong influence on the void content and on the fibre/matrix interface strength but not on the matrix elastic modulus. The interlaminar shear strength was mainly controlled by the void content under low cure pressure. When cure pressure reaches $0.4 \mathrm{MPa}$ and above, ILSS failure modes were dominated by the fibre/matrix interface.

- The damage initiated in the composite laminates was mainly caused by the competing intralaminar and interlaminar damage mechanisms. In this work, intralaminar damage was the dominant mechanism leading to failure in the short beam bending tests.

- Micromechanical modelling was demonstrated to be an efficient means to predict intralaminar material characterisation and associated non-linear shear behaviour.

- The mesoscale model, based on the predicted intralaminar material properties from the micromechanical model, and measured interlaminar properties, were shown to successfully capture the mesoscale failure with high accuracy both qualitatively and quantitatively. It is worth mentioning the limitation in this work, mesoscale model using measured interlaminar properties makes this sequential multiscale model not fully predictive. A more detailed study for predicting interlaminar properties from a computational micromechanical model should be considered in the future.

This work makes a significant contribution to the understanding of the effect of cure cycle pressure on the interfacial properties at different length scales, providing the basis for multiscale modelling of composite structures which account for processing parameters. This will lead to more efficient and rapidly obtained designs, reduce uncertainty, accelerate materials development, transform the engineering design optimization process and unify design and manufacturing.

\section{Acknowledgments}

The authors would like to gratefully acknowledges the funding from the Major State Basic Research Development Program of China (973 Program) under Grant No. 2014 CB046502 and State Key Laboratory of High-performance Complex Manufacturing under Grant No. ZZYJKT2016-04. B. G. Falzon would also like to acknowledge the financial support of Bombardier and the Royal Academy of Engineering. 


\section{References}

[1] Tan W, Falzon BG, Chiu LN, Price M. Predicting low velocity impact damage and CompressionAfter-Impact (CAI) behaviour of composite laminates. Composites Part A: Applied Science and Manufacturing. 2015;71:212-226.

[2] Tan W, Falzon BG. Modelling the crush behaviour of thermoplastic composites. Composites Science and Technology. 2016;134:57-71.

[3] Camanho PP, Dávila CG. Mixed-mode decohesion finite elements for the simulation of delamination in composite materials. 2002.

[4] Maimí P, Camanho PP, Mayugo J, Dávila C. A continuum damage model for composite laminates: Part I-Constitutive model. Mechanics of Materials. 2007;39(10):897-908.

[5] Pinho S, Iannucci L, Robinson P. Physically-based failure models and criteria for laminated fibrereinforced composites with emphasis on fibre kinking: Part I: Development. Composites Part A: Applied Science and Manufacturing. 2006;37(1):63-73.

[6] Mahboob Z, Chemisky Y, Meraghni F, Bougherara H. Mesoscale modelling of tensile response and damage evolution in natural fibre reinforced laminates. Composites Part B: Engineering. 2017;119:168-183.

[7] Treutenaere S, Lauro F, Bennani B, Matsumoto T, Mottola E. Modelling of the intralaminar matrix damage with friction effects of fabric reinforced polymers. Composites Part B: Engineering.

2017;111:60-73.

[8] Patel BP, Gupta AK. An investigation on nonlocal continuum damage models for composite laminated panels. Composites Part B: Engineering. 2014;60:485-494.

[9] O'Dwyer D, O'Dowd N, McCarthy C. Investigation of strain hardening effects under in-plane shear of unidirectional composite materials. Computational materials science. 2012;64:179-182.

[10] Tan W, Falzon BG. Modelling the nonlinear behaviour and fracture process of AS4/PEKK thermoplastic composite under shear loading. Composites Science and Technology. 2016;126:60-77. [11] Tan W, Falzon BG, Price M, Liu H. The role of material characterisation in the crush modelling of thermoplastic composite structures. Composite Structures. 2016;153:914-927.

[12] Naya F, González C, Lopes CS, Van der Veen S, Pons F. Computational micromechanics of the transverse and shear behavior of unidirectional fiber reinforced polymers including environmental effects. Composites Part A: Applied Science and Manufacturing. 2017;92:146-157.

[13] Canal LP, González C, Segurado J, Llorca J. Intraply fracture of fiber-reinforced composites: Microscopic mechanisms and modeling. Composites Science and Technology. 2012;72(11):12231232.

[14] Krause D. A physically based micromechanical approach to model damage initiation and evolution of fiber reinforced polymers under fatigue loading conditions. Composites Part B:

Engineering. 2016;87:176-195.

[15] Lopes CS, González C, Falcó O, Naya F, LLorca J, Tijs B. Multiscale virtual testing: the roadmap to efficient design of composites for damage resistance and tolerance. CEAS Aeronautical Journal. 2016;7(4):607-619.

[16] LLorca J, González C, Molina-Aldareguía JM, Segurado J, Seltzer R, Sket F, et al. Multiscale modeling of composite materials: a roadmap towards virtual testing. Advanced materials.

2011;23(44):5130-5147.

[17] González C, Vilatela J, Molina-Aldareguía J, Lopes C, LLorca J. Structural composites for multifunctional applications: current challenges and future trends. Progress in Materials Science. 2017.

[18] Drucker DC, Prager W. Soil mechanics and plastic analysis or limit design. Quarterly of applied mathematics. 1952;10(2):157-165.

[19] Lubliner J, Oliver J, Oller S, Oñate E. A plastic-damage model for concrete. International Journal of Solids and Structures. 1989;25(3):299-326.

[20] Li X, Gao W, Liu W. Post-buckling progressive damage of CFRP laminates with a large-sized elliptical cutout subjected to shear loading. Composite Structures. 2015;128:313-321. 
[21] Zhao L, Wang Y, Zhang J, Gong Y, Hu N, Li N. XFEM-based model for simulating zigzag delamination growth in laminated composites under mode I loading. Composite Structures.

2017;160:1155-1162.

[22] Melro AR, Camanho PP, Andrade Pires FM, Pinho ST. Micromechanical analysis of polymer composites reinforced by unidirectional fibres: Part II - Micromechanical analyses. International Journal of Solids and Structures. 2013;50(11):1906-1915.

[23] Vaughan TJ, McCarthy CT. A combined experimental-numerical approach for generating statistically equivalent fibre distributions for high strength laminated composite materials. Composites Science and Technology. 2010;70(2):291-297.

[24] ABAQUS V. 6.14 Documentation. Dassault Systemes Simulia Corporation. 2014.

[25] Totry E, Molina-Aldareguía JM, González C, Llorca J. Effect of fiber, matrix and interface properties on the in-plane shear deformation of carbon-fiber reinforced composites. Composites Science and Technology. 2010;70(6):970-980.

[26] Puck A, Schürmann H. Failure analysis of FRP laminates by means of physically based phenomenological models. Compos Sci Technol. 1998;58(7):1045-1067.

[27] Catalanotti G, Camanho PP, Marques AT. Three-dimensional failure criteria for fiber-reinforced laminates. Composite Structures. 2013;95:63-79.

[28] Tan W, Falzon BG, Price M. Predicting the crushing behaviour of composite material using highfidelity finite element modelling. International Journal of Crashworthiness. 2015;20(1):60-77.

[29] Donadon M, Iannucci L, Falzon BG, Hodgkinson J, de Almeida SF. A progressive failure model for composite laminates subjected to low velocity impact damage. Computers \& Structures. 2008;86(11):1232-1252.

[30] Press WH. Numerical recipes in Fortran 77: the art of scientific computing: Cambridge university press; 1992.

[31] Fleming DC. Modelling composite crushing initiation using a cohesive element formulation. Int J Crash. 2011;16(5):475-485.

[32] Chamis C, Sendeckyj G. Critique on theories predicting thermoelastic properties of fibrous composites. Journal of Composite Materials. 1968;2(3):332-358.

[33] Simulia. Abaqus 6.12 documentation. Providence, Rhode Island, US. 2012.

[34] Benzeggagh M, Kenane M. Measurement of mixed-mode delamination fracture toughness of unidirectional glass/epoxy composites with mixed-mode bending apparatus. Composites Science and Technology. 1996;56(4):439-449.

[35] Ogihara S, Koyanagi J. Investigation of combined stress state failure criterion for glass fiber/epoxy interface by the cruciform specimen method. Composites Science and Technology. 2010;70(1):143-150.

[36] Hernández S, Sket F, Molina-Aldaregu1'a JM, González C, Llorca J. Effect of curing cycle on void distribution and interlaminar shear strength in polymer-matrix composites. Composites Science and Technology. 2011;71(10):1331-1341.

[37] Cytec. CYCOM X850 Material Datasheet. GROUP CS. 2013.

[38] Medina M C, Molina-Aldareguia JM, Gonzalez C, Melendrez MF, Flores P, Llorca J.

Comparison of push-in and push-out tests for measuring interfacial shear strength in nano-reinforced composite materials. Journal of Composite Materials. 2015.

[39] Rodríguez M, Molina-Aldareguía JM, González C, Llorca J. A methodology to measure the interface shear strength by means of the fiber push-in test. Composites Science and Technology.

2012;72(15):1924-1932.

[40] Johnson AC, Hayes SA, Jones FR. The role of matrix cracks and fibre/matrix debonding on the stress transfer between fibre and matrix in a single fibre fragmentation test. Composites Part A:

Applied Science and Manufacturing. 2012;43(1):65-72.

[41] Li M, Liu H, Gu Y, Li Y, Zhang Z. Effects of carbon fiber surface characteristics on interfacial bonding of epoxy resin composite subjected to hygrothermal treatments. Applied Surface Science.

2014;288:666-672. 
[42] Gaur U, Miller B. Microbond method for determination of the shear strength of a fiber/resin interface: evaluation of experimental parameters. Composites science and technology. 1989;34(1):3551.

[43] ASTM. Standard Test Method for Short-Beam Strength of Polymer Matrix Composite Materials and Their Laminates. ASTM International; 2016.

[44] Zidi M, Carpentier L, Chateauminois A, Sidoroff F. Quantitative analysis of the microindentation behaviour of fibre-reinforced composites: development and validation of an analytical model. Composites science and technology. 2000;60(3):429-437.

[45] Kharrat M, Chateauminois A, Carpentier L, Kapsa P. On the interfacial behaviour of a glass/epoxy composite during a micro-indentation test: assessment of interfacial shear strength using reduced indentation curves. Composites Part A: Applied Science and Manufacturing. 1997;28(1):3946.

[46] Oliver WC, Pharr GM. Measurement of hardness and elastic modulus by instrumented indentation: Advances in understanding and refinements to methodology. Journal of materials research. 2004;19(01):3-20.

[47] Ma X, Gu Y, Li M, Li Y, Zhang D, Jia L, et al. Properties of carbon fiber composite laminates fabricated by coresin film infusion process for different prepreg materials. Polymer Composites. 2013;34(12):2008-2018.

[48] Sun J, Li M, Gu Y, Zhang D, Li Y, Zhang Z. Interply friction of carbon fiber/epoxy prepreg stacks under different processing conditions. Journal of Composite Materials.

2013:0021998313476320.

[49] Chang T, Zhan L, Tan W, Li S. Void content and interfacial properties of composite laminates under different autoclave cure pressure. Composite Interfaces. 2017;24(5):529-540.

[50] Agius SL, Magniez KJC, Fox BL. Cure behaviour and void development within rapidly cured out-of-autoclave composites. Composites Part B: Engineering. 2013;47:230-237.

[51] Gu Y, Li M, Zhang Z, Sun Z. Void formation model and measuring method of void formation condition during hot pressing process. Polymer Composites. 2010;31(9):1562-1571.

[52] Drzal L, Madhukar M. Fibre-matrix adhesion and its relationship to composite mechanical properties. Journal of Materials Science. 1993;28(3):569-610.

[53] Nardin M, Schultz J. Relationship between fibre-matrix adhesion and the interfacial shear strength in polymer-based composites. Composite Interfaces. 1993;1(2):177-192.

[54] Naya F, Herráez M, Lopes C, González C, Van der Veen S, Pons F. Computational micromechanics of fiber kinking in unidirectional FRP under different environmental conditions. Composites Science and Technology. 2017;144:26-35.

[55] Varandas LF, Arteiro A, Bessa MA, Melro AR, Catalanotti G. The effect of through-thickness compressive stress on mode II interlaminar crack propagation: A computational micromechanics approach. Composite Structures. 2017;182:326-334.

[56] Gilabert FA, Garoz D, Paepegem WV. Macro- and micro-modeling of crack propagation in encapsulation-based self-healing materials: Application of XFEM and cohesive surface techniques.

Materials \& Design. 2017;130:459-478.

[57] Zurich E.Aerospace Structures. http://www.structures.ethz.ch/research/aerospace-structures. 2017-07-27 


\section{Figures}

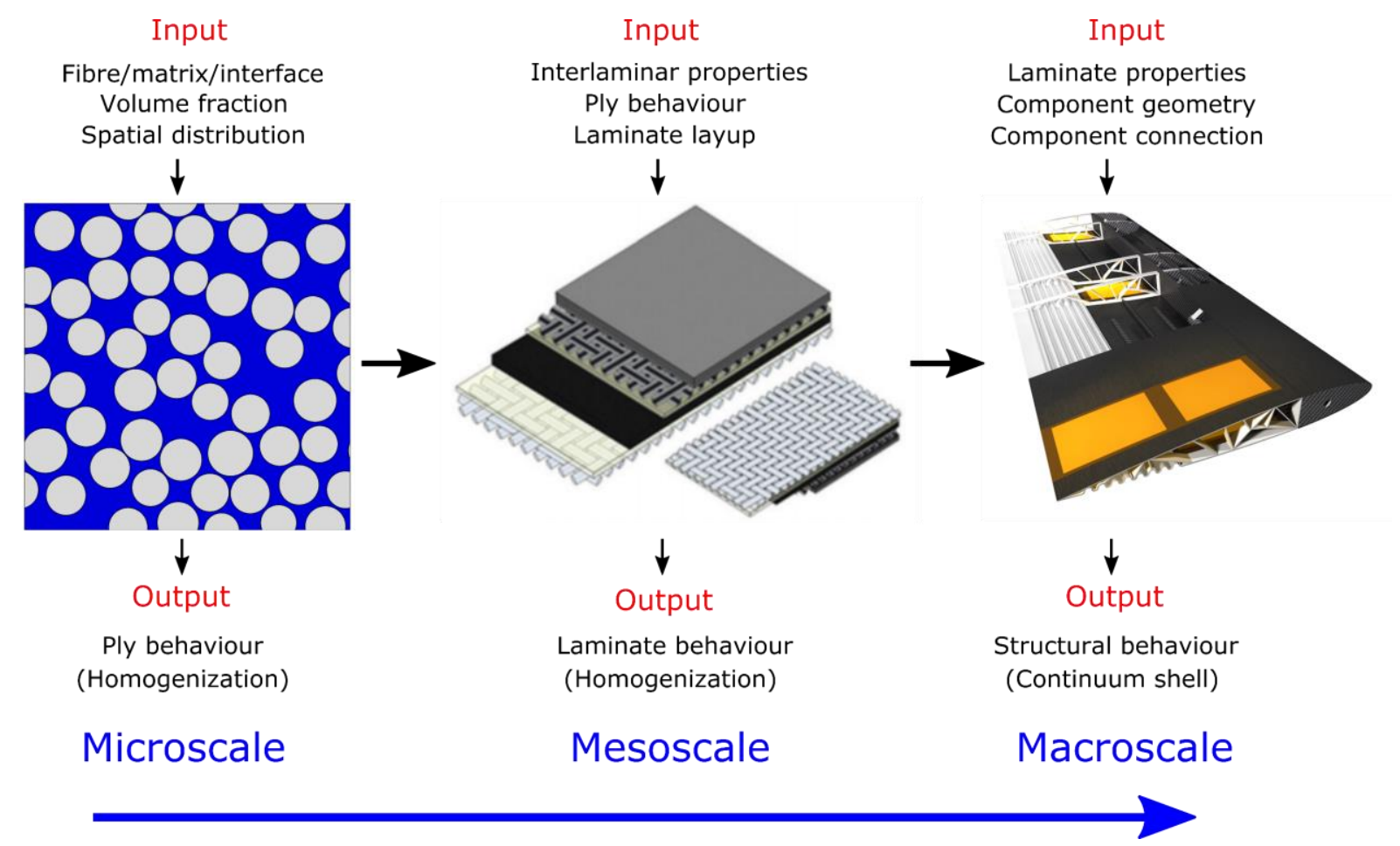

Figure 1. Schematic of bottom-up multi-scale modelling of engineering composite structures [15, 57] 


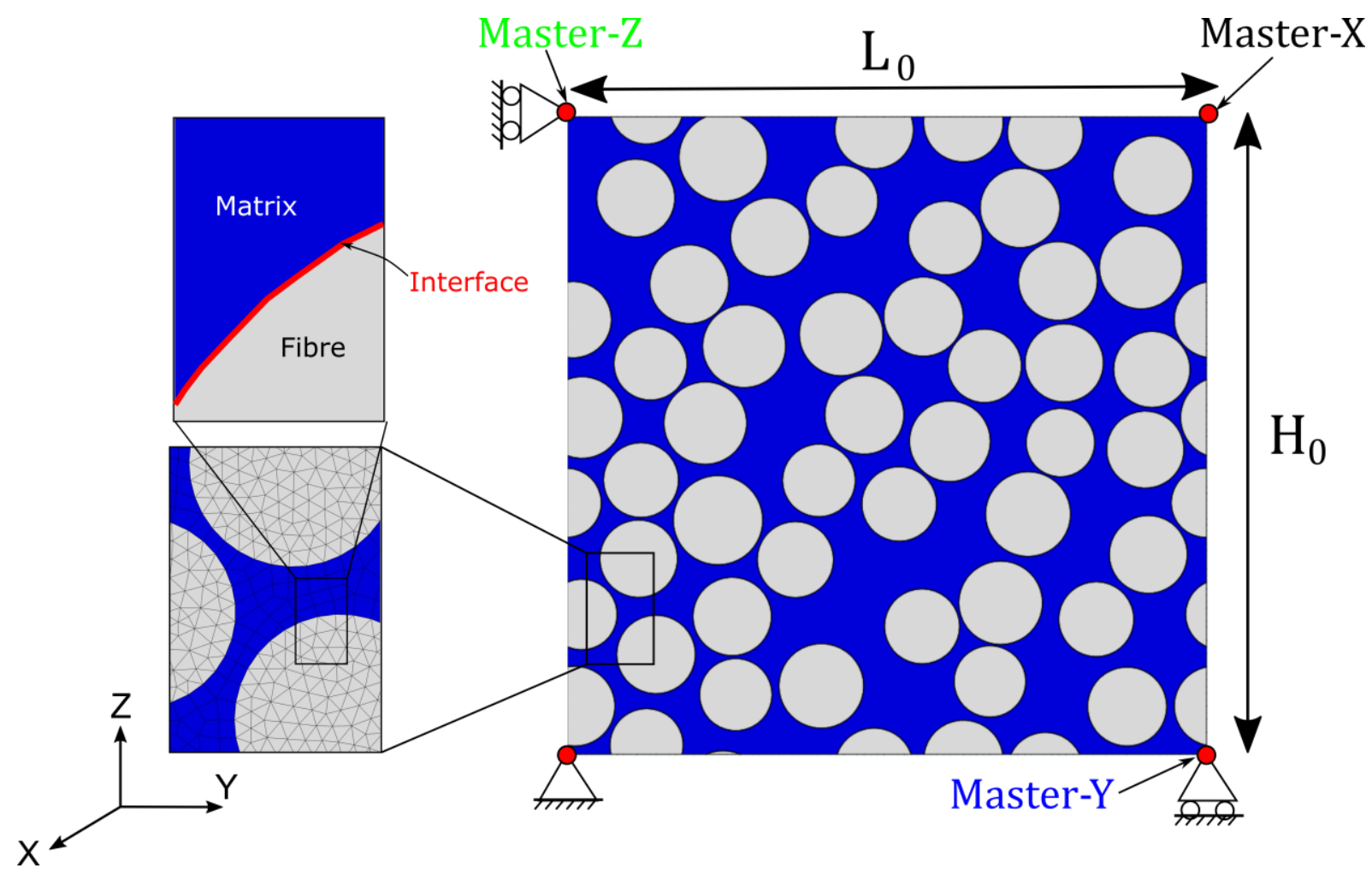

Figure 2. Schematic 2D view of the microscale RVE model showing the fibre distribution, FEM mesh, cohesive interface and periodic boundary conditions (PBC)

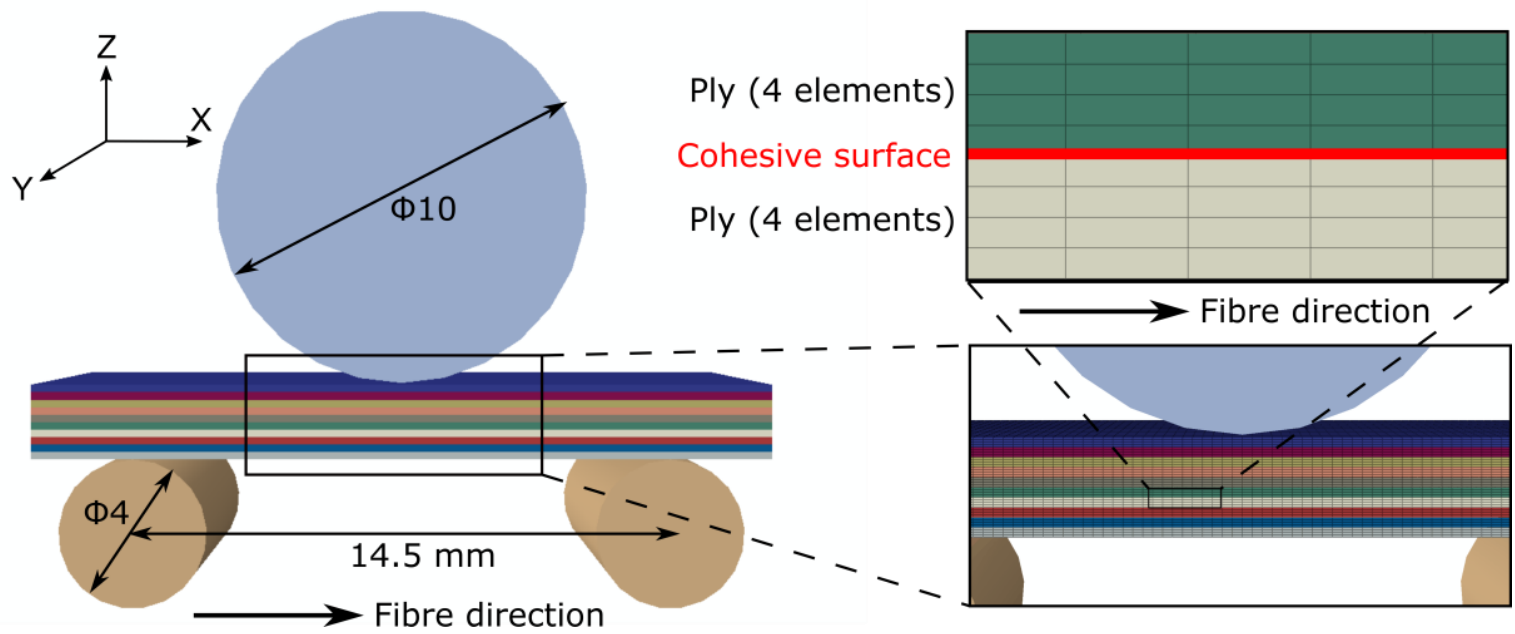

Figure 3. Schematic 3D view of the mesoscale model showing SSB, FEM mesh, interlaminar cohesive interface 


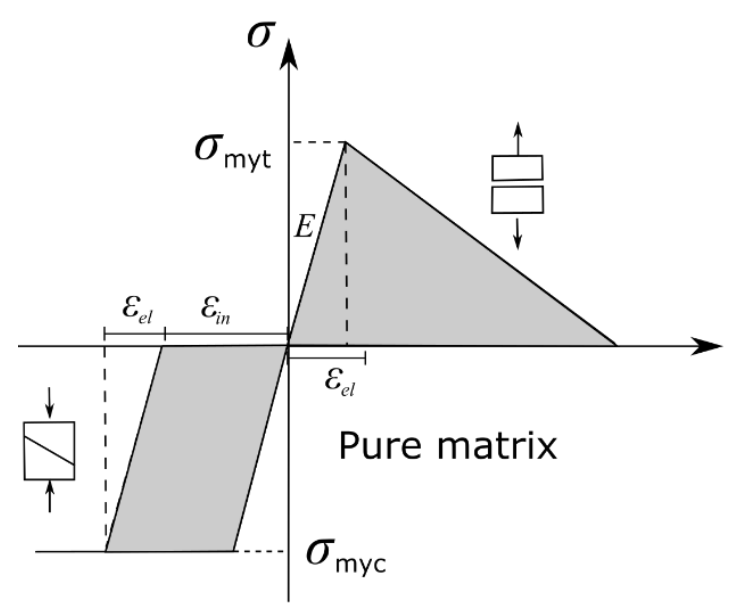

(a)

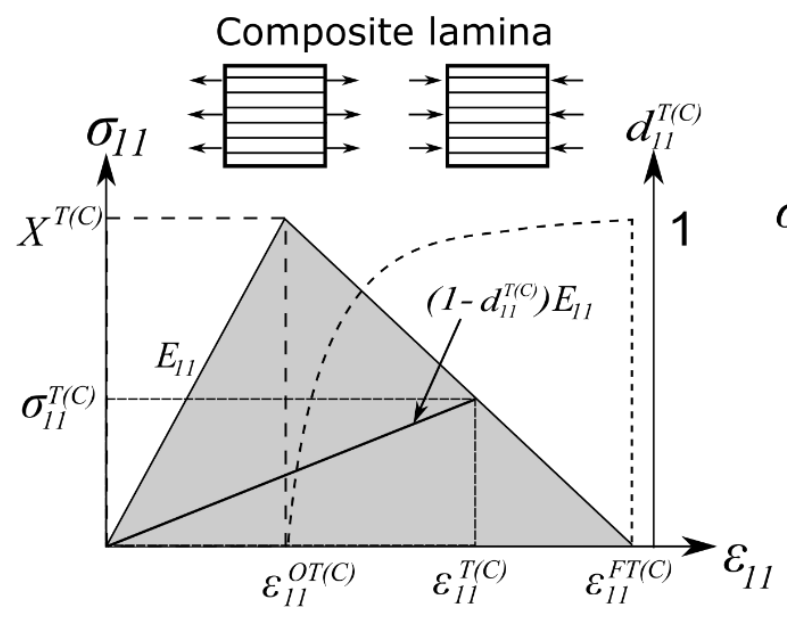

(c)

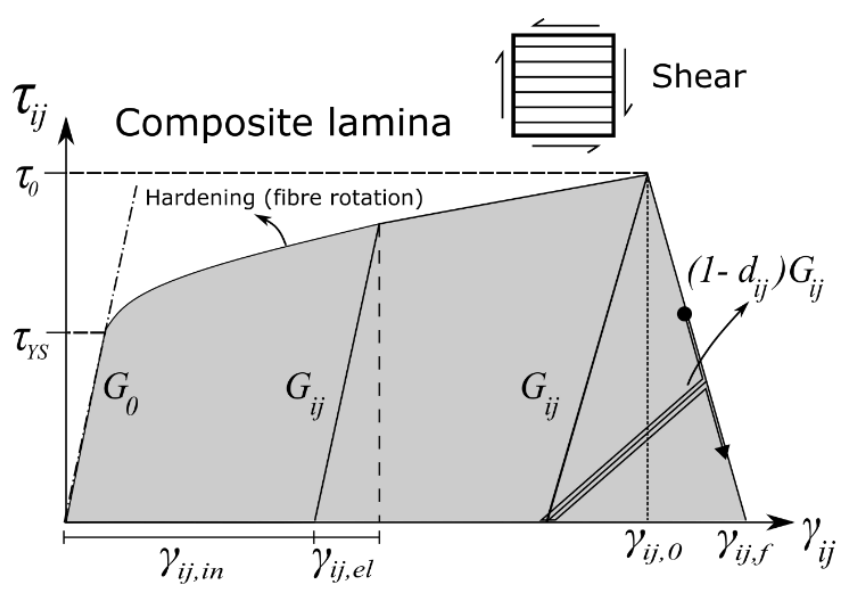

(b)

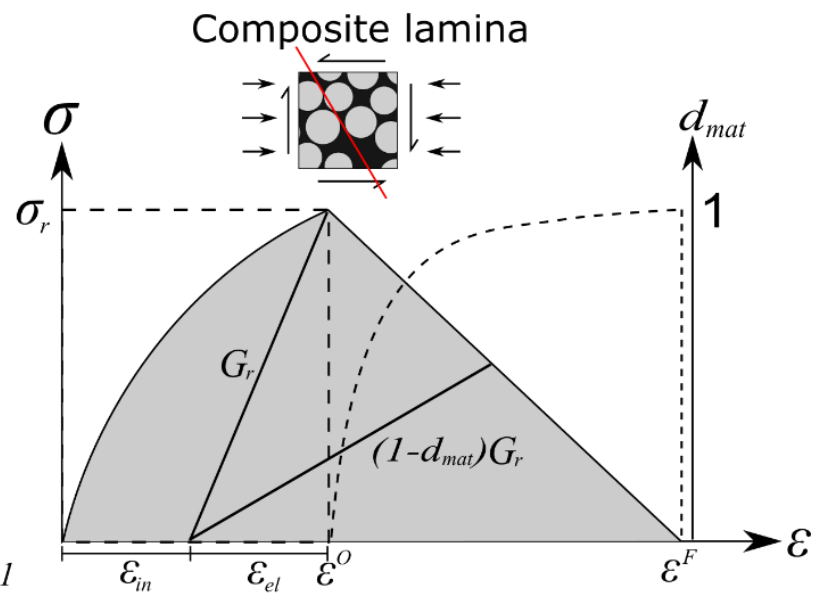

(d)

Figure 4. Schematic of constitutive laws (a) microscale-model: pure matrix under tension and compression, mesoscale model: (b) non-linear shear behaviour of composite lamina considering geometrical hardening associated with fibre rotation (c) elastic behaviour and damage evolution of composite laminar under longitudinal tension and compression (d) non-linear behaviour of composite laminar under 3D combined compression and shear loading 


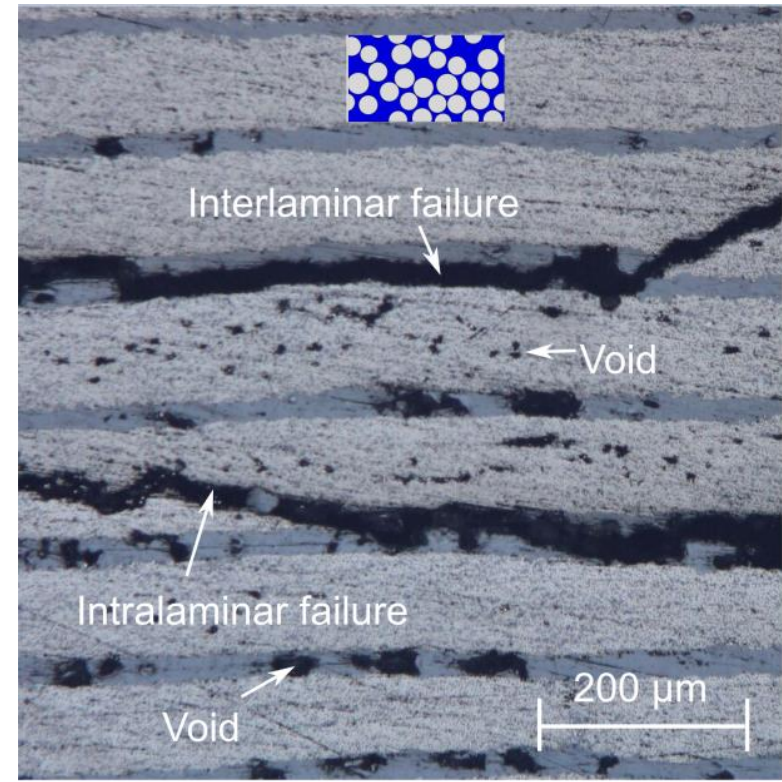

(a)

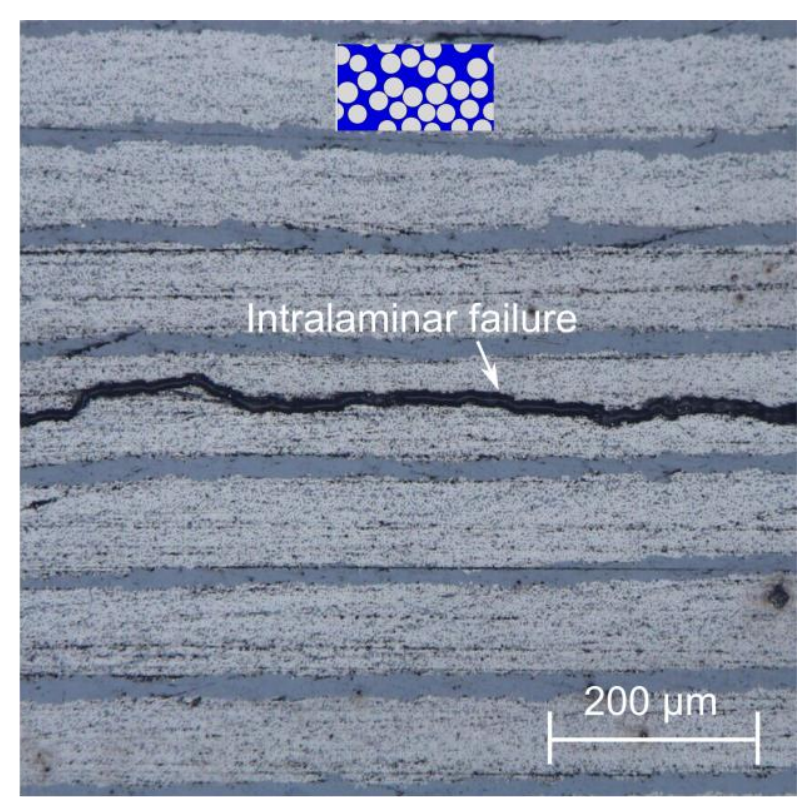

(b)

Figure 5. Optical microscopy images of crack propagation within composite laminates under short-beam bending tests using different autoclave pressure of (c) $0.2 \mathrm{MPa}$ and (d) $0.6 \mathrm{MPa}$, inset schematic figures indicating fibre orientation

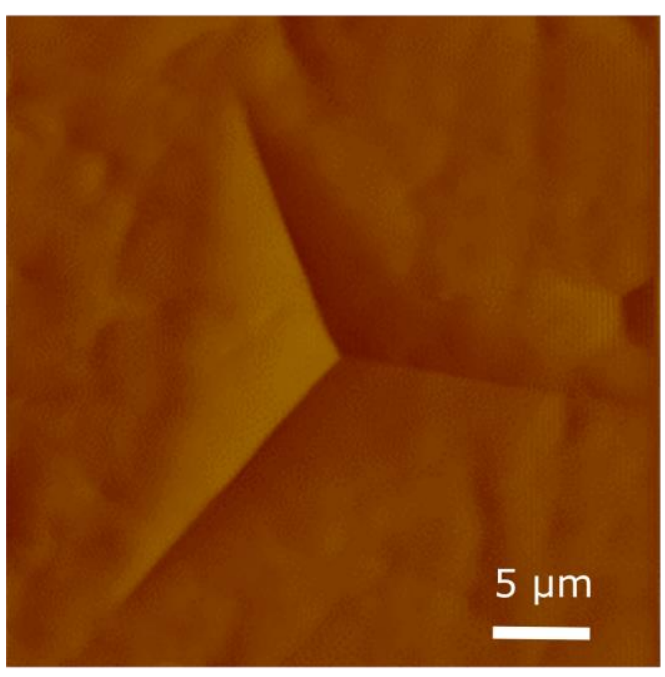

(a)

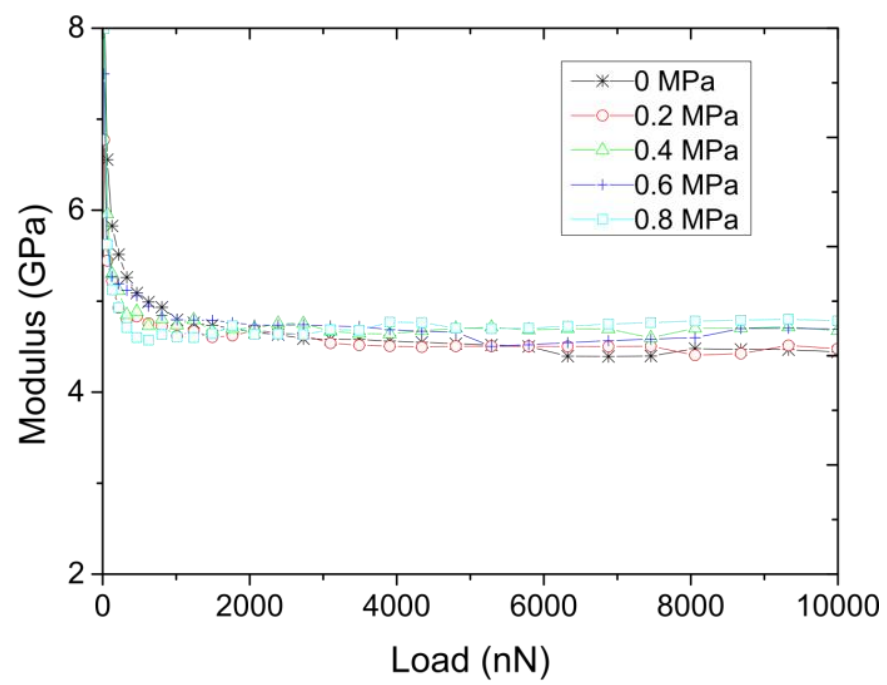

(b)

Figure 6. (a) Imprint of the Berkovich tip in a matrix pocket within the laminate. (b) Influence of the indentation depth on the elastic modulus of the resin. 


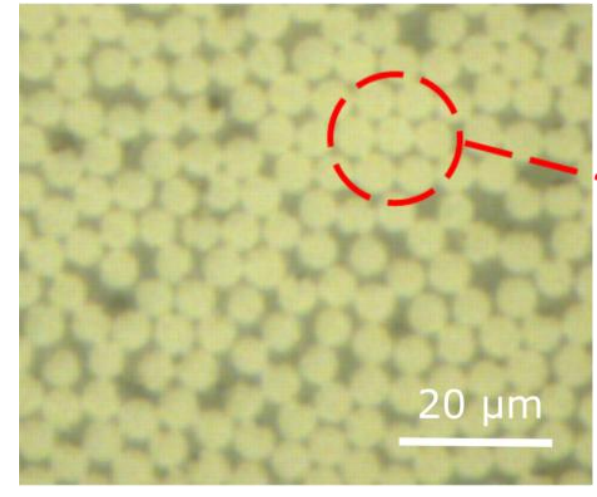

(a)

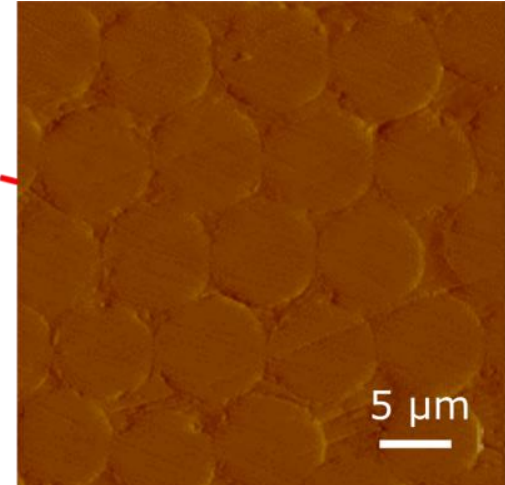

(b)

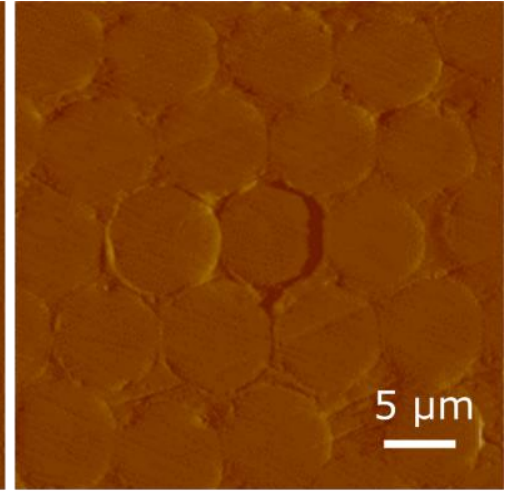

(c)

Figure 7. (a) Optical micrograph of composite cross-section (b) In-situ imaging showing the detail of one hexagonal packing before and (c) after the fibre push-in test.

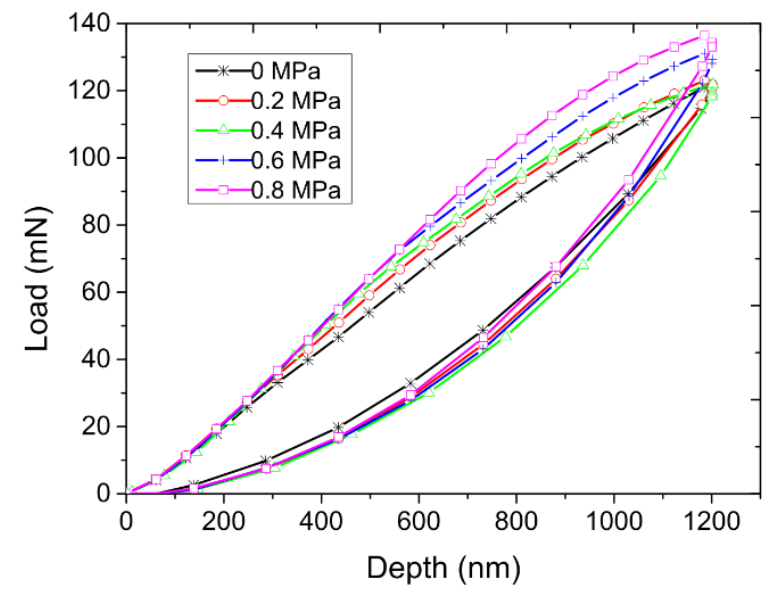

(a)

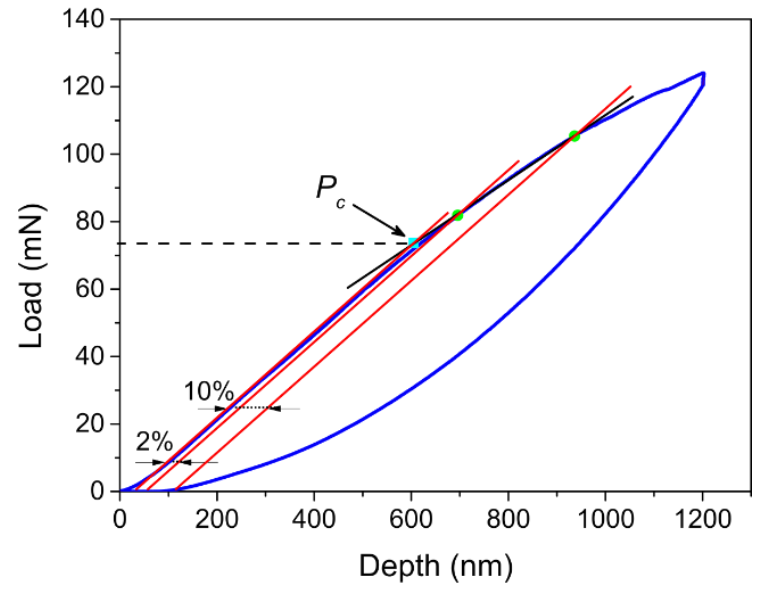

(b)

Figure 8. (a) Representative load-indentation depth curves of fibres pushed-in in laminates manufactured with different pressure. (b) Methodology to determine the critical load at the onset of interface debonding 


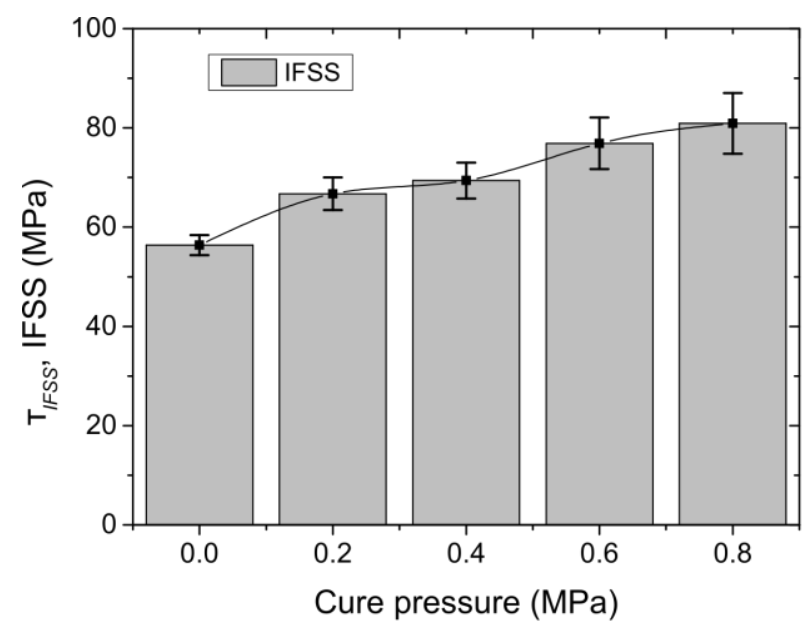

(a)

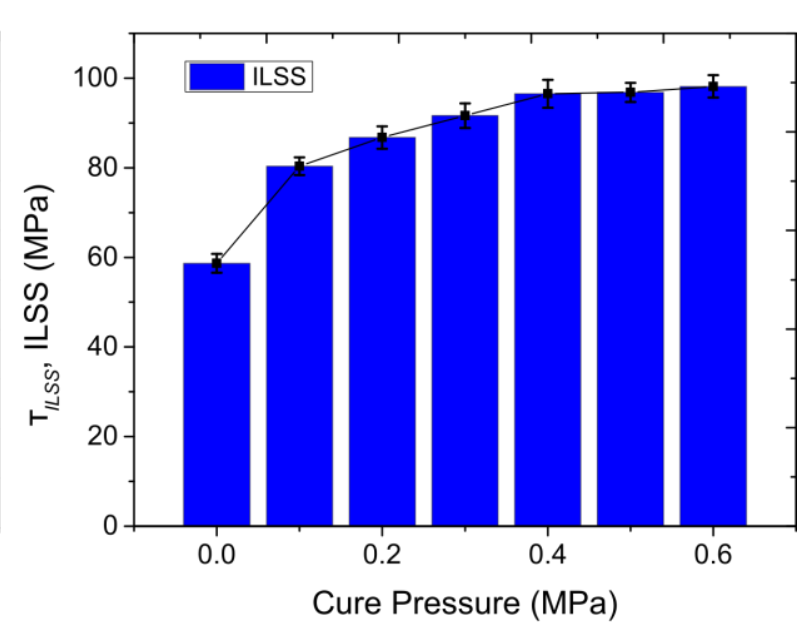

(b)

Figure 9. Evolution of (a) the fibre/matrix interfacial shear strength and (b)interlaminar shear strength (ILSS) as a function of the autoclave pressure.

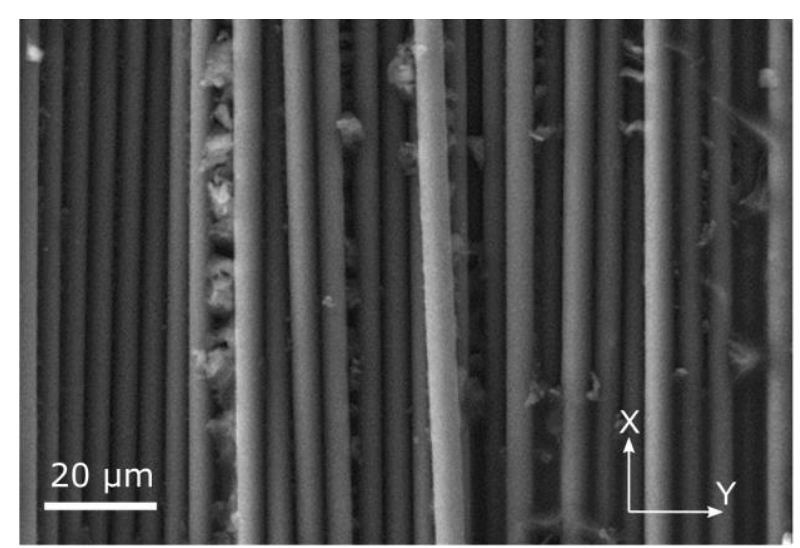

(a) $0 \mathrm{MPa}$

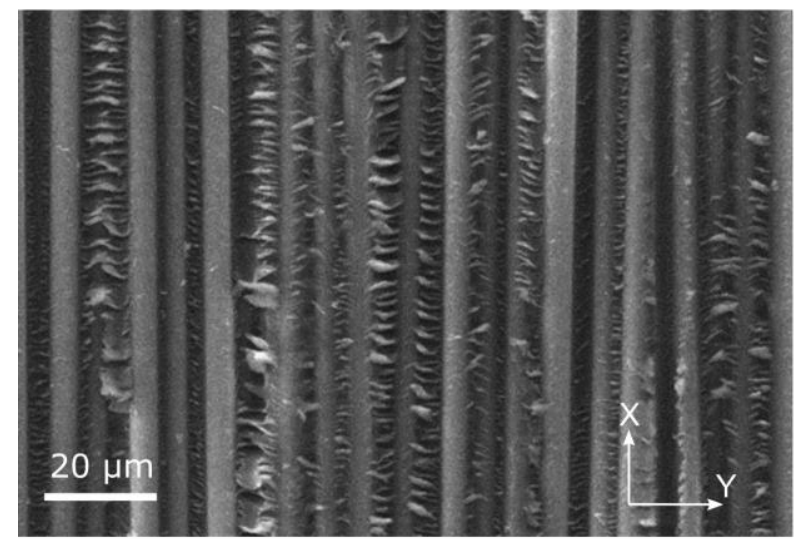

(c) $0.6 \mathrm{MPa}$

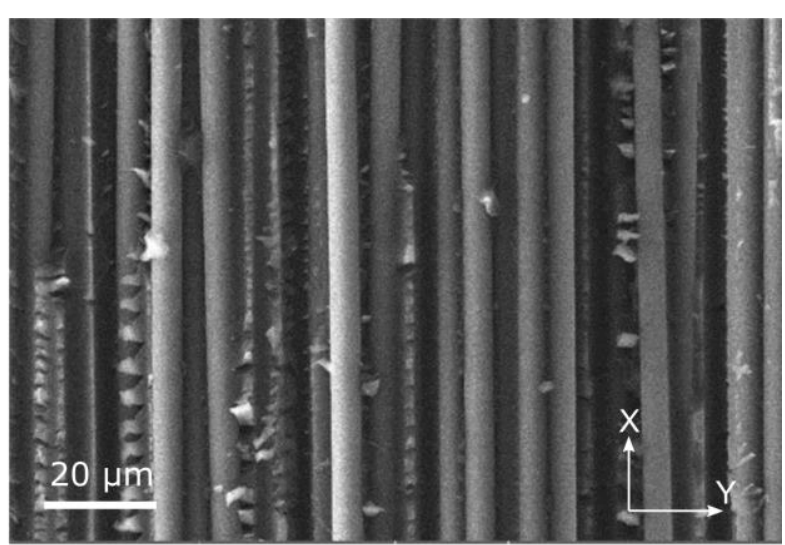

(b) $0.2 \mathrm{MPa}$

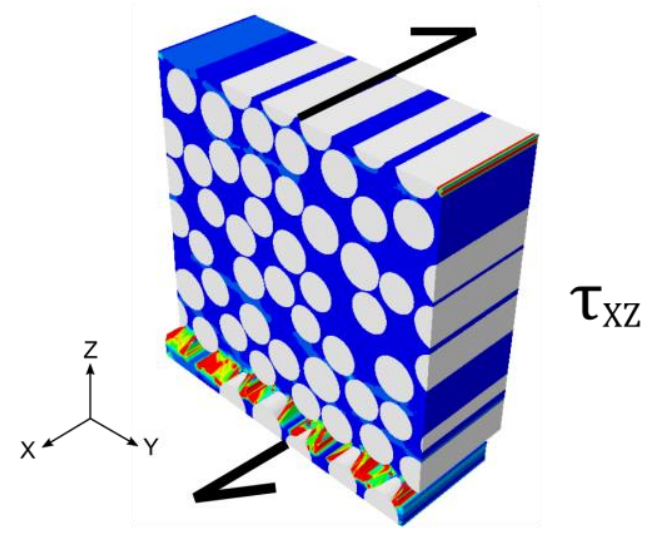

(d) Intralaminar shear fracture 
Figure 10. Scanning electron micrographs of the fracture surfaces of specimens tested in three-point bending to measure the ILSS. (a) Autoclave pressure $0 \mathrm{MPa}$. (b) $0.2 \mathrm{MPa}$. (c) $0.6 \mathrm{MPa}$.(d) Schematic of intralaminar shear fracture

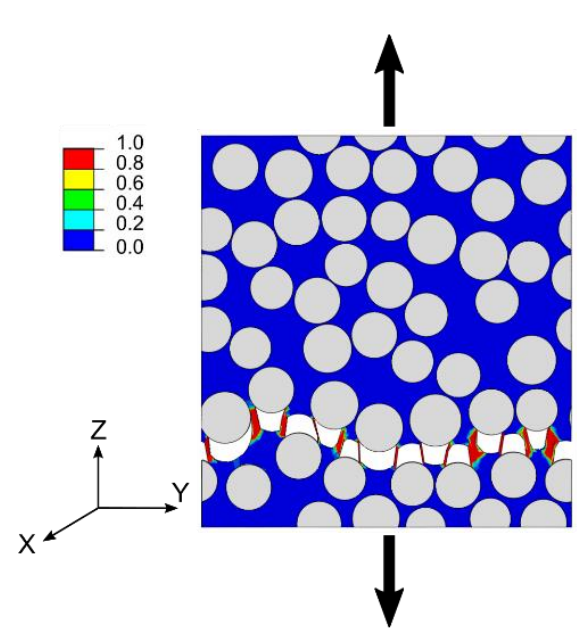

(a)

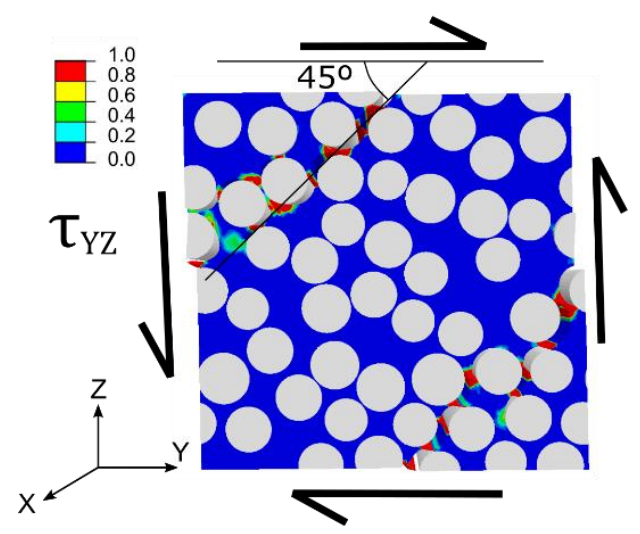

(c)

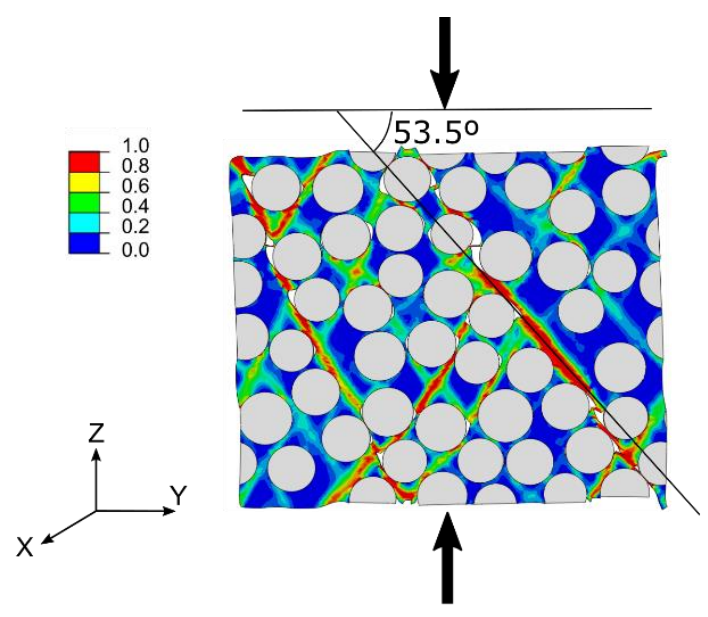

(b)
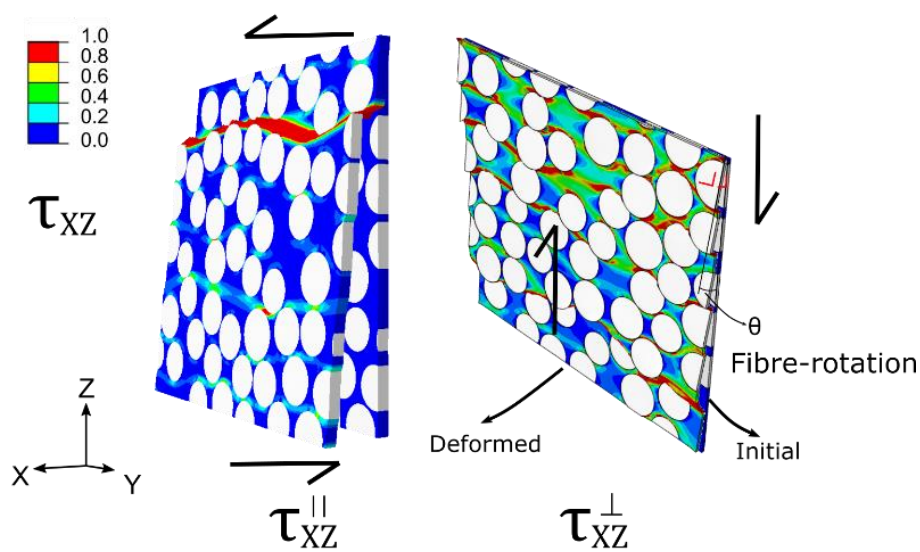

(d)

Figure 11. Predicted damage contours under (a) transverse tension (b) transverse compression (c) out-of-plane shear (d) in-plane shear with shear perpendicular to fibre and shear parallel to fibre 


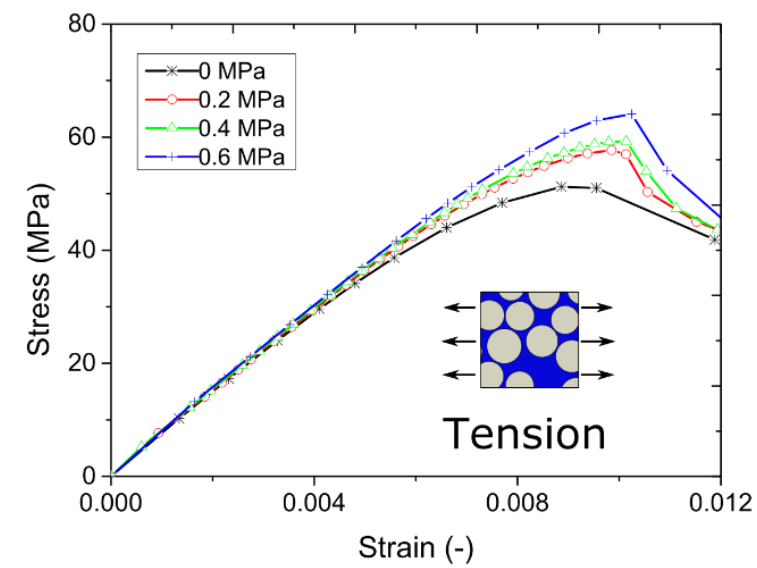

(a)

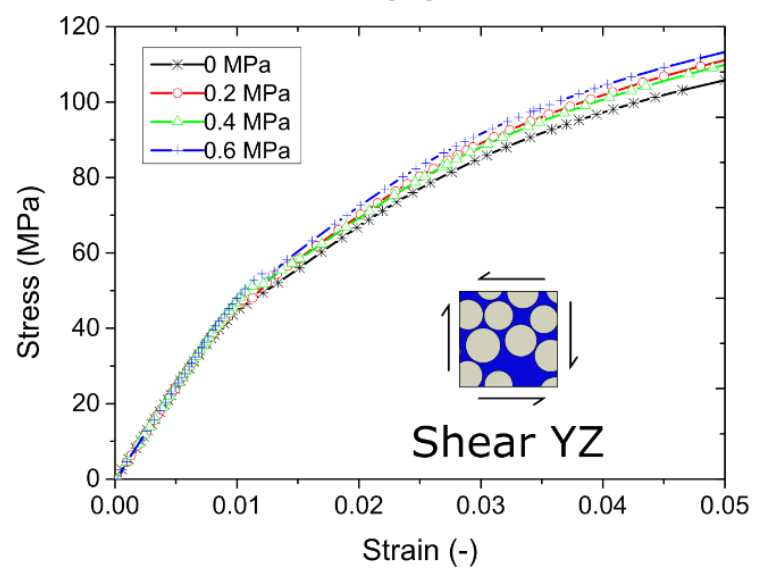

(c)

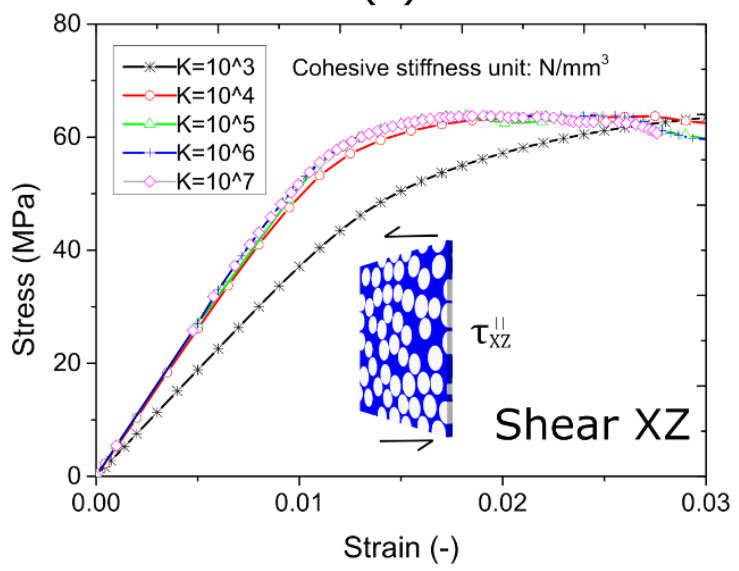

(e)

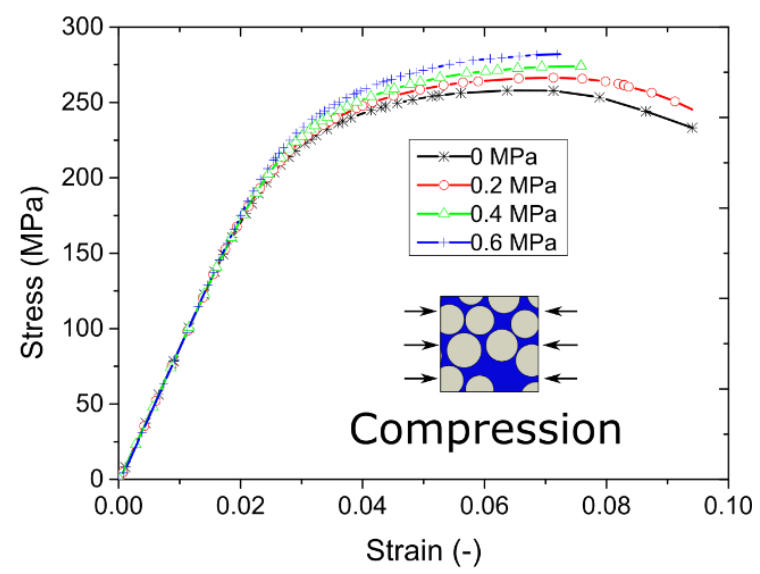

(b)

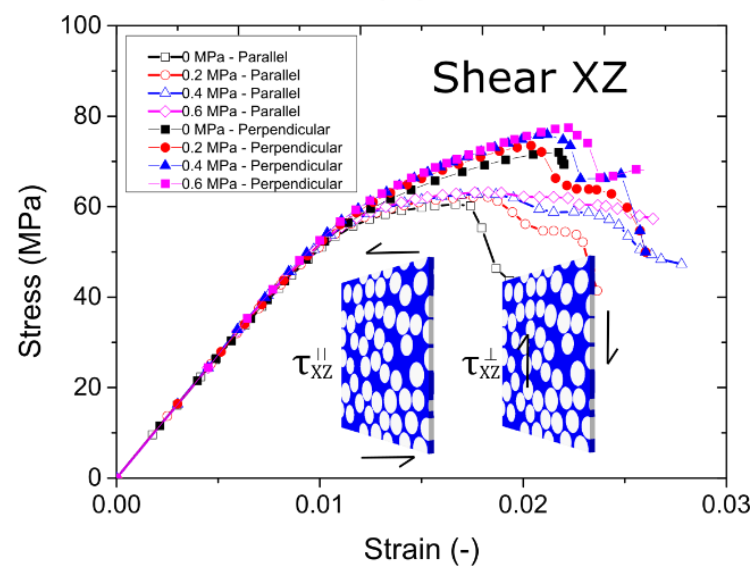

(d)

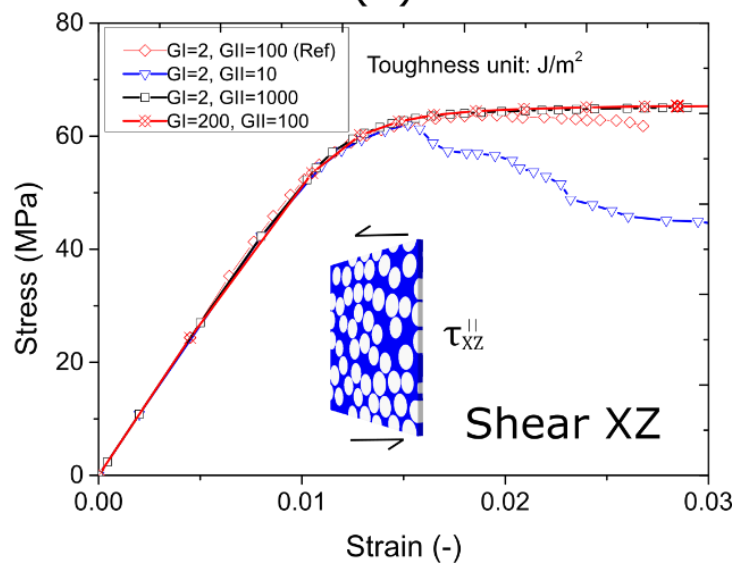

(f)

Figure 12. Predicted stress-strain curves under (a) transverse tension (b) transverse compression (c) shear perpendicular to fibre and (d) shear parallel to fibre with interface properties under various cure pressure with and without fibre rotation, (e) cohesive stiffness without fibre rotation and (f) fracture toughness without fibre

$$
\text { rotation }
$$




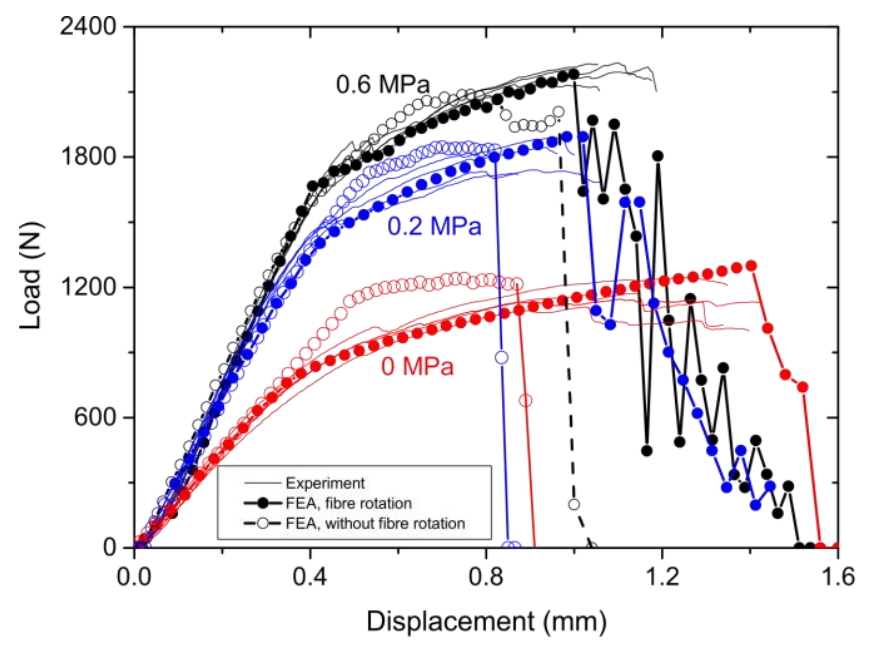

(a)

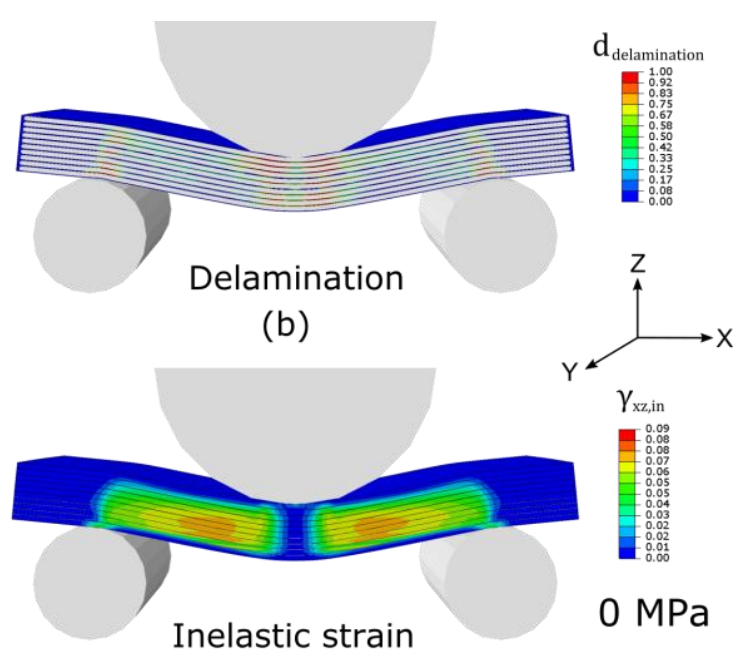

(c)

Figure 13. (a) Experimental and numerical load-displacement curves of short beam bending tests for composite laminates (b) Interlaminar failure of numerical test samples and (c) Inelastic shear strain $\gamma_{X Z}$ of SSB numerical test on sample cured under 0 MPa pressure 
$0 \mathrm{MPa}$
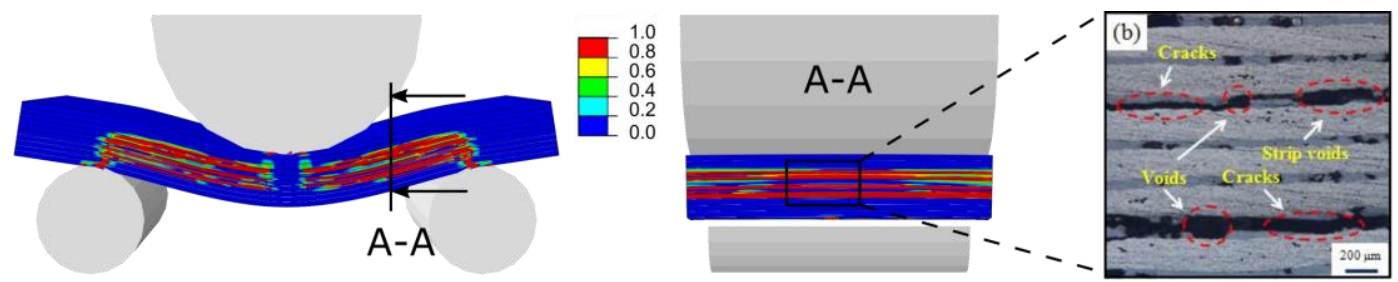

(a)
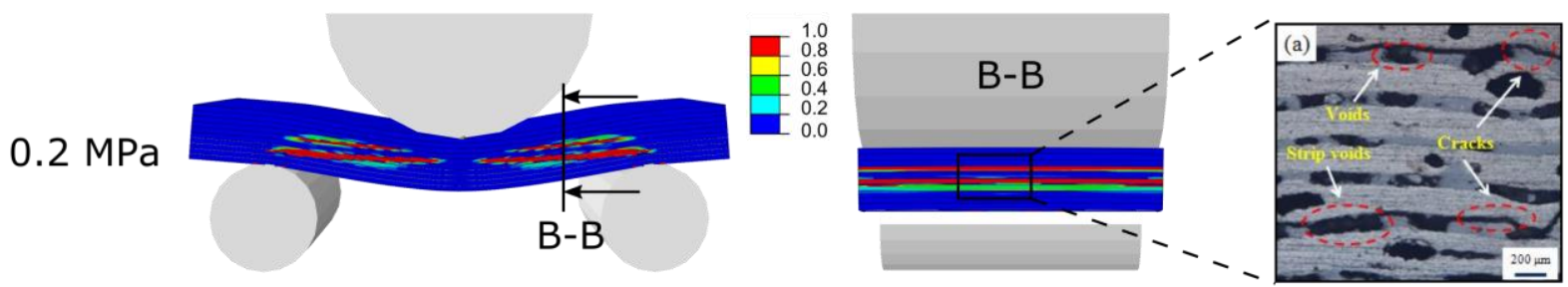

(b)
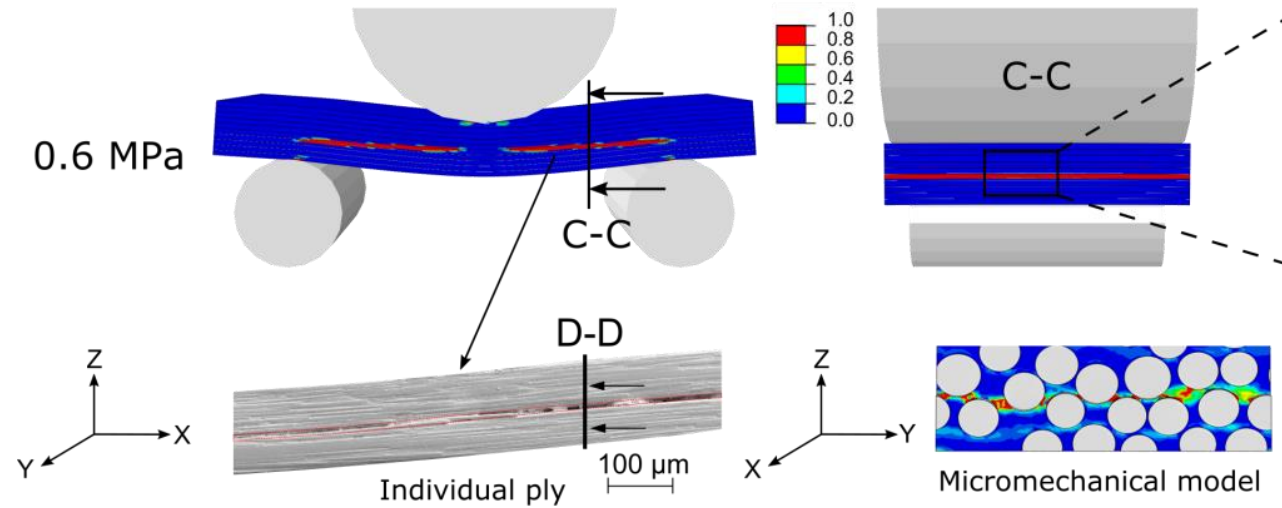

(c)

Figure 14. Virtual tests using mesoscale model to predict the intralaminar and interlaminar shear failure with interfacial properties under cure pressure of (a) $0 \mathrm{MPa}$ (b) $0.2 \mathrm{MPa}$ (c) $0.6 \mathrm{MPa}$ with inset SEM images (below) as SSB shear failure modes within an individual ply in $\mathrm{XZ}$ and $\mathrm{YZ}$ plane, micromechanical model indicating similar crack path with the experimental results 


\section{Tables}

Table 1. Thermo-elastic material properties of T800/X850: matrix, fibres and the homogenized composite [20, 21].

\begin{tabular}{cccccccc}
\hline Material & $\boldsymbol{E}_{\mathbf{1}}(\mathrm{GPa})$ & $\boldsymbol{E}_{\mathbf{2}}(\mathrm{GPa})$ & $\boldsymbol{G}_{\mathbf{1 2}(\mathbf{1 3})}$ & $\boldsymbol{G}_{\mathbf{2 3}}$ & $\boldsymbol{v}_{\mathbf{1 2}}$ & $\boldsymbol{\alpha}_{\mathbf{1}}$ & $\boldsymbol{\alpha}_{\mathbf{2}}$ \\
& & & $(\mathrm{GPa})$ & $(\mathrm{GPa})$ & & $\left(\mathbf{1 0}^{-\mathbf{6}} /{ }^{\circ} \mathrm{C}\right)$ & $\left(\mathbf{1 0}^{-\mathbf{6}} /{ }^{\circ} \mathrm{C}\right)$ \\
\hline Fibre & 282 & 11.38 & 6.37 & 3.84 & 0.33 & -0.56 & 5.6 \\
Matrix & 4.68 & 4.68 & 1.80 & 1.80 & 0.35 & 40 & 40 \\
Composite & 185 & 9.03 & 4.75 & 3.15 & 0.34 & 13.6 & \\
\end{tabular}

Table 2. Input material parameters for RVE in micromechanical model

\begin{tabular}{cc}
\hline Pressure (MPa) & Values \\
\hline 0 & $t_{3}^{0}=37 \mathrm{MPa}, t_{1(2)}^{0}=56 \mathrm{MPa}, \mathcal{G}_{I c}=0.66 \mathrm{~J} / \mathrm{m}^{2}, \mathcal{G}_{I I c}=33 \mathrm{~J} / \mathrm{m}^{2}$ \\
0.2 & $t_{3}^{0}=44 \mathrm{MPa}, t_{1(2)}^{0}=66 \mathrm{MPa}, \mathcal{G}_{I c}=1.25 \mathrm{~J} / \mathrm{m}^{2}, \mathcal{G}_{I I c}=62 \mathrm{~J} / \mathrm{m}^{2}$ \\
0.4 & $t_{3}^{0}=46 \mathrm{MPa}, t_{1(2)}^{0}=69 \mathrm{MPa}, \mathcal{G}_{I c}=1.6 \mathrm{~J} / \mathrm{m}^{2}, \mathcal{G}_{I I c}=80 \mathrm{~J} / \mathrm{m}^{2}$ \\
0.6 & $t_{3}^{0}=51 \mathrm{MPa}, t_{1(2)}^{0}=76 \mathrm{MPa}, \mathcal{G}_{I c}=2 \mathrm{~J} / \mathrm{m}^{2}, \mathcal{G}_{I I c}=100 \mathrm{~J} / \mathrm{m}^{2}$ \\
Shared values & $50 \mathrm{MPa}, \mathcal{G}_{m}=100 \mathrm{~J} / \mathrm{m}^{2}$ \\
\end{tabular}


Table 3. Experimental characterization of fibre/matrix interfacial shear strength (IFSS) and interlaminar shear strength (ILSS)

\begin{tabular}{ccccc}
\hline \multirow{2}{*}{ Pressure (MPa) } & Intraply void (Exp) & Interply void (Exp) & IFSS (Exp) & ILSS (Exp) \\
\cline { 2 - 5 } & Percentage (\%) & Percentage (\%) & Strength (MPa) & Strength (MPa) \\
\hline 0 & $8.0 \pm 0.91$ & $26.0 \pm 1.81$ & $56 \pm 2.1$ & $58 \pm 2.1$ \\
0.2 & $4.4 \pm 0.46$ & $6.2 \pm 0.82$ & $66 \pm 3.3$ & $86 \pm 2.5$ \\
0.4 & $3.1 \pm 0.29$ & $0.2 \pm 0.05$ & $69 \pm 3.6$ & $95 \pm 3.1$ \\
0.6 & $0.5 \pm 0.17$ & $0.1 \pm 0.03$ & $76 \pm 5.2$ & $96 \pm 2.1$ \\
\hline
\end{tabular}

Table 4. Numerically-predicted from RVE vs. experimentally-characterized elastic constants, transverse and shear strengths for a T800/X850 ply

\begin{tabular}{ccccccc}
\hline Pressure (MPa) & $E_{22}(\mathrm{GPa})$ & $\varepsilon_{22}(\%)$ & $S_{12(13)}^{A *}(\mathrm{MPa})$ & $G_{13}(\mathrm{GPa})$ & $Y_{T}(\mathrm{MPa})$ & $Y_{C}(\mathrm{MPa})$ \\
\hline 0 (Num) & $8.69 \pm 0.19$ & $0.91 \pm 0.10$ & $65 \pm 1.9$ & 4.58 & $51 \pm 0.5$ & $258 \pm 2.7$ \\
0.2 (Num) & $8.76 \pm 0.17$ & $0.95 \pm 0.08$ & $68 \pm 1.5$ & 4.61 & $57 \pm 1.7$ & $266 \pm 4.3$ \\
0.4 (Num) & $8.89 \pm 0.15$ & $0.11 \pm 0.05$ & $70 \pm 1.0$ & 4.63 & $59 \pm 2.1$ & $274 \pm 5.7$ \\
0.6 (Num) & $9.01 \pm 0.12$ & $0.12 \pm 0.04$ & $75 \pm 0.8$ & 4.66 & $64 \pm 3.8$ & $282 \pm 6.9$ \\
& & & & & & \\
$0.6($ Exp) * & $8.75 \sim 9.13$ & $0.10 \sim 0.15$ & $70 \sim 80$ & $4.56 \sim 4.75$ & $68 \sim 90$ & $290 \sim 312$
\end{tabular}

* Experimental data from authors and published literature $[20,21], S_{12(13)}^{A}$ is the average shear strength of values $\tau_{X Z}^{\|}$and $\tau_{X Z}^{\perp}$ considering fibre rotation effect 
Table 5. Material properties of T800/X850 composite laminates for meso-scale model considering resin-rich layer $(30 \mu \mathrm{m})$ and void contents, unassigned properties were given from RVE prediction

\begin{tabular}{lc}
\hline Pressure & Values \\
\hline $0 \mathrm{MPa}$ & $\mathrm{E}_{11}=94 \mathrm{GPa}, t_{3}^{0}=39.1 \mathrm{MPa}, t_{1(2)}^{0}=58.7 \mathrm{MPa}, c_{1}=17.4, c_{2}=-118, \tau_{13}^{Y}=50 \mathrm{MPa}$ \\
$0.2 \mathrm{MPa}$ & $\mathrm{E}_{11}=132 \mathrm{GPa}, t_{3}^{0}=57.8 \mathrm{MPa}, t_{1(2)}^{0}=86.8 \mathrm{MPa}, c_{1}=12.2, c_{2}=-101, \tau_{13}^{Y}=54 \mathrm{MPa}$ \\
$0.6 \mathrm{MPa}$ & $\mathrm{E}_{11}=148 \mathrm{GPa}, t_{3}^{0}=65.4 \mathrm{MPa}, t_{1(2)}^{0}=98.4 \mathrm{MPa}, \mathrm{c}_{1}=7.1, \mathrm{c}_{2}=-94, \tau_{13}^{Y}=60 \mathrm{MPa}$ \\
& $X_{T}=3041 \mathrm{MPa}, X_{C}=1747 \mathrm{MPa}, \Gamma_{11}^{\mathrm{T}}=133 \mathrm{~kJ} / \mathrm{m}^{2}, \Gamma_{11}^{\mathrm{C}}=40 \mathrm{~kJ} / \mathrm{m}^{2}, \Gamma_{22}^{\mathrm{T}}=\Gamma_{22}^{\mathrm{C}}=\Gamma_{12}=$ \\
value [21] & $\Gamma_{23}=\Gamma_{13}=1.6 \mathrm{~kJ} / \mathrm{m}^{2}, G_{I C}=0.35 \mathrm{~kJ} / \mathrm{m}^{2}, G_{I I C}=3 \mathrm{~kJ} / \mathrm{m}^{2}, \eta=2$
\end{tabular}

* (a). Homogeneous elastic properties considering the void content based on estimated by means of Chamis rule of mixtures [32]; (b) fracture toughness $\Gamma_{i j}^{\mathrm{T}(\mathrm{C})}(i, j=1,2,3)$, is estimated from a similar material system

T700/M21 [1], as the main failure mechanism here is not fibre breakage/kinking, the effect of these values is limited; (c). The interlaminar fracture toughness for $0 \mathrm{MPa}$ and $0.2 \mathrm{MPa}$ are using $G_{I c, I I c}^{\text {void }}=$ $G_{I c, I I C}\left[\mathbf{1}-\left(\frac{\mathbf{4} f_{\text {void }}}{\pi}\right)^{\mathbf{1} / \mathbf{2}}\right][36]$ as a reasonable approximation. 